\title{
A Reappraisal on the Potential Ability of Human Neutrophils to Express and Produce IL-17 Family Members In Vitro: Failure to Reproducibly Detect It
}

\begin{abstract}
Nicola Tamassia ${ }^{1 \dagger}$, Fabio Arruda-Silva ${ }^{1,2 \dagger}$, Federica Calzetti', Silvia Lonardi ${ }^{3}$, Sara Gasperini', Elisa Gardiman', Francisco Bianchetto-Aguilera', Luisa Benerini Gatta ${ }^{3}$, Giampiero Girolomoni ${ }^{4}$, Alberto Mantovani ${ }^{5,6,7}$, William Vermi ${ }^{3}$ and Marco A. Cassatella ${ }^{1 *}$
\end{abstract}

\section{OPEN ACCESS}

Edited by:

Liwu Li,

Virginia Tech, United States

Reviewed by:

Min Wu,

University of North Dakota,

United States

Petya Dimitrova,

Institute of Microbiology,

Sofia, Bulgaria

${ }^{*}$ Correspondence:

Marco A. Cassatella

marco.cassatella@univr.it

tThese authors have contributed equally to this work.

Specialty section:

This article was submitted to Molecular Innate Immunity, a section of the journal

Frontiers in Immunology

Received: 14 February 2018 Accepted: 03 April 2018

Published: 17 April 2018

Citation:

Tamassia N, Arruda-Silva F, Calzetti F, Lonardi S, Gasperini S, Gardiman E,

Bianchetto-Aguilera F, Gatta LB, Girolomoni G, Mantovani A, Vermi W

and Cassatella MA (2018)

A Reappraisal on the Potential Ability of Human Neutrophils to Express and Produce IL-17 Family

Members In Vitro: Failure to Reproducibly Detect It.

Front. Immunol. 9:795. doi: 10.3389/fimmu.2018.00795
${ }^{1}$ Department of Medicine, Section of General Pathology, University of Verona, Verona, Italy, ${ }^{2}$ CAPES Foundation, Ministry of Education of Brazil, Brasilia, Brazil, ${ }^{3}$ Department of Molecular and Translational Medicine, Section of Pathology, University of Brescia, Brescia, Italy, ${ }^{4}$ Department of Medicine, Section of Dermatology and Venereology, University of Verona, Verona, Italy, ${ }^{5}$ Humanitas Clinical and Research Center, Rozzano, Italy, ${ }^{6}$ Humanitas University, Pieve Emanuele, Italy, ${ }^{7}$ The William Harvey Research Institute, Queen Mary University of London, London, United Kingdom

Neutrophils are known to perform a series of effector functions that are crucial for the innate and adaptive responses, including the synthesis and secretion of a variety of cytokines. In light of the controversial data in the literature, the main objective of this study was to more in-depth reevaluate the capacity of human neutrophils to express and produce cytokines of the IL-17 family in vitro. By reverse transcription quantitative real-time PCR, protein measurement via commercial ELISA, immunohistochemistry $(\mathrm{IHC})$ and immunofluorescence $(\mathrm{IF})$, flow cytometry, immunoblotting, chromatin immunoprecipitation (ChIP), and ChIP-seq experiments, we found that highly pure (>99.7\%) populations of human neutrophils do not express/produce IL-17A, IL-17F, IL-17AF, or IL-17B mRNA/protein upon incubation with a variety of agonists. Similar findings were observed by analyzing neutrophils isolated from active psoriatic patients. In contrast with published studies, IL-17A and IL-17F mRNA expression/production was not even found when neutrophils were incubated with extremely high concentrations of IL-6 plus IL-23, regardless of their combination with inactivated hyphae or conidia from Aspergillus fumigatus. Consistently, no deposition of histone marks for active (H3K27Ac) and poised (H3K4me1) genomic regulatory elements was detected at the IL-17A and IL-17F locus of resting and IL-6 plus IL-23-stimulated neutrophils, indicating a closed chromatin conformation. Concurrent experiments revealed that some commercial anti-IL-17A and anti-IL-17B antibodies (Abs), although staining neutrophils either spotted on cytospin slides or present in inflamed tissue samples by IHC/IF, do not recognize intracellular protein having the molecular weight corresponding to IL-17A or IL-17B, respectively, in immunoblotting experiments of whole neutrophil lysates. By contrast, the same Abs were found to more specifically recognize other intracellular proteins of neutrophils, suggesting that their ability to positively stain neutrophils in cytospin preparations and, eventually, tissue samples derives from IL-17A- or IL-17B-independent detections. In 
sum, our data confirm and extend, also at epigenetic level, previous findings on the inability of highly purified populations of human neutrophils to express/produce IL-17A, IL-17B, and IL-17F mRNAs/proteins in vitro, at least under the experimental conditions herein tested. Data also provide a number of justifications explaining, in part, why it is possible to false positively detect IL-17A+-neutrophils.

Keywords: neutrophils, IL-17 members, IL-17A, IL-17B, IL-17F

\section{INTRODUCTION}

The IL-17 family of cytokines consists of six members, namely IL-17A (usually referred to as IL-17), IL-17B, IL-17C, IL-17D, IL-17E (also known as IL-25), and IL-17F (1). After the discovery of a subtype of $\mathrm{CD}^{+} \mathrm{T}$ helper, expressing IL-17A and IL-17F (currently known as Th17 cells), plenty of studies have been published correlating Th17 cells with a wide range of physiological and pathological processes. IL-17A and IL-17F are not only the most studied but also the most closely related, since they share $50 \%$ of amino acid sequence identity, adjacent gene localization (2) and binding to the same IL-17R, in this case composed by the IL-17RA and IL-17RC subunits (1). The IL-17R group comprises, in fact, five receptor subunits, IL-17RA, IL-17RB, IL-17RC, IL-17RD, and IL-17RE (3). IL-17RA was the first to be described, is ubiquitously expressed (particularly in hematopoietic cells), and functions as a common receptor subunit used by at least four ligands, namely IL-17A, IL-17C, IL-17E, and IL-17F (3). IL-17F is often coproduced with IL-17A, so that together they can also form an IL-17F/IL-17A heterodimer (4) binding to the IL-17RA/ IL17RC complex as either homodimers or heterodimers (3). IL-17A and IL-17F are proinflammatory cytokines that play key regulatory roles in host defense and inflammatory diseases. They mainly mediate immune regulatory functions by promoting the generation of proinflammatory cytokines/growth factors (including G-CSF, GM-CSF, and IL-6) and chemokines (such as CXCL8, CXCL6, and CXCL1) by epithelial and other stromal cells, which ultimately lead to the attraction and activation of neutrophils and macrophages into the inflammatory site (5), as well as to granulopoeisis (6). Although crucial in protecting the host from invasion by many types of pathogens, including bacteria and fungi (7), dysregulated IL-17A and IL-17F production can lead to the development of autoimmune diseases, such as psoriasis, multiple sclerosis, and rheumatoid arthritis (RA), as well as cancer progression $(5,8)$. The latter observations hence make IL-17A/F as a very important target for the development of new therapies $(1,8)$.

As mentioned, Th17 cells are considered the main sources of IL-17A and IL-17F. However, other innate immune cells produce these cytokines, including $\gamma \delta \mathrm{T}$ cells, natural killer $\mathrm{T}$ cells, invariant natural killer cells, Paneth cells, TCR $\beta^{+}$natural Th17 cells, lymphoid-tissue inducer-like cells, IL-17-expressing type 3 innate lymphoid cells, and mast cells $(8,9)$. By contrast, it is still questionable whether human polymorphonuclear neutrophils represent sources of IL-17A or IL-17F. It is currently well established that neutrophils are crucial players in innate immune responses, not only for their capacity to perform defensive functions (10) but also for their ability to produce a large variety of cytokines (11). Concerning IL-17A and/or IL-17F, in 2010, we reported that highly purified populations of human neutrophils (>99.7\%), incubated for up to $20 \mathrm{~h}$ with IFN $\gamma$ and/or LPS in vitro, do not produce IL-17A (12). While a few papers substantially confirm our findings (13-17), the majority of the subsequent studies report that human neutrophils may represent sources of IL-17A (18-53). Experimental evidence proving that human neutrophils express IL-17A mostly, but not only, derives by immunohistochemistry (IHC) and/or immunofluorescence (IF) studies documenting IL-17 $\mathrm{A}^{+}$-neutrophils in tissue specimens from a variety of pathological conditions $(18,19,21,22,25,27$, 28, 30-32, 34, 36-39, 41-43, 45, 47-49, 51, 53). Interestingly, many of these studies focus on psoriasis $(20,25,30,32,35,49)$, a disease characterized by an early accumulation of neutrophils in skin lesions in which neutrophil-derived mediators (such as reactive oxygen species, granule proteins, and cytokines) may alter the homeostatic state of keratinocytes and endothelial cells (54). At the end of 2014, however, Tamarozzi et al. (13) not only reported the absence of IL-17A mRNA expression and production by highly pure (99.9\%) populations of resting or activated neutrophils but also demonstrated that some of the commercial polyclonal anti-IL-17A antibodies (Abs) stain neutrophils for their non-specific recognition of various intracellular proteins different from antigenic IL-17A. Nevertheless, reports describing either IL-17A-positive neutrophils in tissue samples from diseases or in vitro-stimulated neutrophils as sources of IL-17A, continue to be published $(20,23,24,26,29,33,35,40,44,46$, $50,52)$. Based on these premises, we decided to more accurately analyze the issue of whether human neutrophils produce IL-17A, as well as other IL-17 members in vitro.

\section{MATERIALS AND METHODS}

\section{Cell Purification and Culture}

Neutrophils were isolated from buffy coats of healthy donors (HDs) and manipulated under endotoxin-free conditions (12). In selected experiments, neutrophils were also isolated from peripheral blood of patients with severe psoriasis, as defined by either $>10 \%$ body surface area involved, or Psoriasis Area and Severity Index score $>10$, or Dermatology Life Quality Index score $>10$ (55). After Ficoll-Paque gradient centrifugation of buffy coats or peripheral blood, followed by dextran sedimentation of granulocytes and hypotonic lysis of erythrocytes, neutrophils were isolated to reach $99.7 \pm 0.2 \%$ purity by positively removing all contaminating cells using the EasySep neutrophil enrichment kit (StemCell Technologies, Vancouver, BC, Canada) (56). Neutrophils were then suspended at $5 \times 10^{6} / \mathrm{ml}$ in RPMI 1640 
medium supplemented with $10 \%$ low $(<0.5 \mathrm{EU} / \mathrm{ml})$ endotoxin FBS (BioWhittaker-Lonza, Basel, Switzerland), incubated with or without $5 \mu \mathrm{M}$ R848, $500 \mu \mathrm{g} / \mathrm{ml}$ particulate $\beta$-glucan (Invivogen, San Diego, CA, USA), $100 \mathrm{ng} / \mathrm{ml}$ ultrapure LPS (from E. coli 0111:B4 strain, Alexis, Enzo Life Sciences, Farmingdale, NY, USA), $1 \mu \mathrm{g} / \mathrm{ml}$ Pam3CSK4 (Invivogen), $50 \mu \mathrm{g} / \mathrm{ml}$ poly(I:C) (Invivogen), $1,000 \mathrm{U} / \mathrm{ml}$ G-CSF (Myelostim, Italfarmaco Spa, Milano, Italy), $100 \mathrm{U} / \mathrm{ml}$ IFN $\gamma$ (R\&D Systems, Minneapolis, MN, USA), $10 \mathrm{ng} / \mathrm{ml}$ GM-CSF (Miltenyi Biotec), $5 \mathrm{ng} / \mathrm{ml}$ TNF $\alpha$ (Peprotech, Rocky Hill, NJ, USA), 2-20 $\mu \mathrm{g} / \mathrm{ml}$ IL-6 (R\&D Systems), 0.2-2 $\mu \mathrm{g} / \mathrm{ml} \mathrm{IL}-23$ (R\&D Systems), 100-500 ng/ml IL-17A (R\&D Systems), $10 \mu \mathrm{g} /$ $\mathrm{ml}$ anti-IL-17A neutralizing Abs (secukinumab, Novartis, Basel, Switzerland), $100 \mathrm{nM} \mathrm{fMLF}, 500 \mu \mathrm{g} / \mathrm{ml}$ curdlan (Sigma, Saint Louis, MO, USA), $20 \mathrm{ng} / \mathrm{ml}$ phorbol mysistate acetate (PMA) (Sigma), $1 \mu \mathrm{g} / \mathrm{ml}$ Ionomycin (Sigma), $100 \mu \mathrm{g} / \mathrm{ml} \mathrm{CpG}$ oligodeoxynucleotides (ODN) (Invivogen), and 1,000 U/ml PEGylated IFN $\alpha-2 a$ (Pegasys, Roche, Basel, Switzerland). Inactivated conidia and hyphae from Aspergillus fumigatus were kindly provided by prof. Luigina Romani (University of Perugia, Italy), and used at a neutrophil-fungi ratio of 1:5 for $A$. fumigatus conidia and 1:1 for A. fumigatus hyphae, as previously described (57). Neutrophils were plated either in 6/24-well tissue culture plates or in polystyrene flasks (from Greiner Bio-One, Kremsmünster, Austria) for culture at $37^{\circ} \mathrm{C}, 5 \% \mathrm{CO}_{2}$ atmosphere. After the desired incubation period, neutrophils were either processed for chromatin immunoprecipitation (ChIP) experiments or collected and spun at $300 \times g$ for $5 \mathrm{~min}$ for other types of assays. In the latter case, cellfree supernatants were immediately frozen in liquid nitrogen and stored at $-80^{\circ} \mathrm{C}$, while the corresponding cell pellets were either extracted for total RNA or lysed for protein analysis. Th1 and Th17 clones (58) were kindly provided by prof. Francesco Annunziato (University of Firenze). CD4 ${ }^{+} \mathrm{T}$ cells were isolated by CD $4^{+} \mathrm{T}$ Cell Isolation Kit (Miltenyi Biotec) and stimulated for up $72 \mathrm{~h}$ with anti-CD3 and anti-CD28 mAbs (5 $\mu \mathrm{g} / \mathrm{ml}$, BD Biosciences).

\section{Flow Cytometry Experiments}

For flow cytometry, $10^{5}$ neutrophils were harvested after the desired treatment, centrifuged, and suspended in $100 \mu \mathrm{l}$ PBS containing $10 \%$ complement-inactivated human serum for Fc $\gamma \mathrm{R}$ blocking. Neutrophils were then stained for $15 \mathrm{~min}$ at T room with: APC anti-human IL-17RA/CD217 (clone 424LTS) and APC mouse $\mathrm{IgG1 \kappa}$, as isotype control (clone P3.6.2.8.1) from eBioscience (San Diego, CA, USA); PE anti-human IL-17RC (clone 309822) and mouse PE IgG2B isotype control from R\&D systems; PE-vio770 anti-human CD11b (clone ICRF44), FITC anti-human CD66b (clone G10F5), and PerCP-Cy5.6 anti-human CD16 (clone 3G8) from BioLegend (San Diego, CA, USA); APC anti-human CD62L (clone 145/15 Miltenyi Biotec), all at working dilutions specified in the corresponding datasheets. Sample fluorescence was then measured by MACSQuant Analyzer (Miltenyi Biotec), while data analysis performed using FlowJo software version 10 from Tree Star (Ashland, OR, USA) (59). For neutrophils of psoriatic patients, $100 \mu$ l whole blood were stained with APC anti-human IL-17RA and PE anti-human IL-17RC Abs in combination with the following mAbs: VioBlue anti-human CD14 (clone TÜK4), PE anti-human CD56 (clone AF12-7H3), PE-Vio770 anti-human CD3 (clone BW264/56), APC anti-human CD19 (clone LT19) from Miltenyi; Brilliant Violet anti-human CD45 (clone 2D1), PerCP-Cy5.5 anti-human CD16 (clone 3G8), and APC-Cy7 antihuman HLA-DR (clone L243) from BioLegend. After red cells lysis by the ammonium chloride buffer, sample fluorescence was immediately measured as previously described.

\section{Superoxide Anion Measurement}

After isolation, neutrophils were suspended at the concentration of $2 \times 10^{6}$ cells $/ \mathrm{ml}$ in HBSS buffer containing $0.5 \mathrm{mM} \mathrm{CaCl}_{2}$ and $1 \mathrm{mg} / \mathrm{ml}$ glucose. Neutrophils $(100 \mu \mathrm{l} /$ well $)$ were then distributed in a 96 -well plate and incubated for $10 \mathrm{~min}$ at $37^{\circ} \mathrm{C}$ prior to the addition of $80 \mu \mathrm{M}$ cytochrome $c, 2 \mathrm{mM} \mathrm{NaN}_{3}$ (Sigma) and the indicated stimuli, including $20 \mathrm{ng} / \mathrm{ml}$ PMA as control. Plates were then incubated at $37^{\circ} \mathrm{C}$ in an automated ELx808IU microplate reader (BioTek Instruments, Inc., Winooski, VT, USA) to record cytochrome $c$ reduction ( $v i a$ absorbance at 550 and $468 \mathrm{~nm}$, at intervals of $5 \mathrm{~min}$ for $90 \mathrm{~min}$ ). $\mathrm{O}_{2}^{-}$production was finally calculated using an extinction coefficient of $24.5 \mathrm{mM}$ (60).

\section{Immunocitochemistry, IHC and IF}

Cytospin preparations of neutrophils (61) previously cultured with the indicated stimuli were stained by ematoxylin and eosin for morphological evaluation. After coverslip removal, specimens were rehydrated through a scale of alcohols, with endogenous peroxidase activity blocked by treatment with $0.3 \% \mathrm{H}_{2} \mathrm{O}_{2}$ in methanol for $20 \mathrm{~min}$. Anti-human IL-17A (AF-317-NA), IL-17B (AF1248), and CXCL8 (AF-208) goat IgG pAbs from R\&D Systems were 1:50 diluted, added to specimens for $60 \mathrm{~min}$ and then revealed using the goat-on-Rodent HRP-polymer (Biocare Medical, Pacheco, CA, USA) followed by diaminobenzidine. Omission of the primary antibody, as well as isotype control staining, was also performed as negative controls. For IL-17A and IL-17B tissue immunostaining, $4-\mu \mathrm{m}$ tissue sections from two FFPE cases of pustular psoriasis were deparaffinized and rehydrated through a scale of alcohols. Endogenous peroxidase activity was then blocked by treatment with $0.3 \% \mathrm{H}_{2} \mathrm{O}_{2}$ in methanol for $20 \mathrm{~min}$. Epitope retrieval was performed using a microwave oven in $1.0 \mathrm{mM}$ EDTA buffer $(\mathrm{pH}$ 8.0), for 3 cycles of $5 \mathrm{~min}$ at $750 \mathrm{~W}$. IL-17A and IL-17B were diluted 1:50 and revealed using the goat HRP-polymer (IHC) or the horse anti-goat IgG biotinylated (Vector Laboratories, Peterborough, UK) followed by streptavidin-FITC (Southern Biotech, Birmingham, AL, USA). DAPI was used for counterstaining. For double IHC, anti-IL-17A and IL-17B Abs were diluted 1:500, and after revelation (as detailed above), anti-CD66b Abs (diluted 1:80 from BioLegend) were added to the sections. Mach4 AP polymer was used as secondary antibody followed by Ferangi Blue as chromogen. Ematoxylin was used for counterstaining.

\section{Cytokine Production}

Cytokine concentrations in cell-free supernatants and cell lysates were measured by commercial enzyme-linked immunosorbent (ELISA) kits, specific for: IL-17A (DY317 from R\&D systems and 88-7176 from eBioscience), IL-17A/F (88-7117, eBioscience), IL-17B [ABKA2223 from Abnova (Taipei, Taiwan) and ab171344 from Abcam (Cambridge, United Kingdom)], IL-17F (887478, eBioscience), and CXCL8 (Mabtech, Nacka Strand, Sweden). ELISA detection limits were $4 \mathrm{pg} / \mathrm{ml}$ (eBioscience) and 
$15.6 \mathrm{pg} / \mathrm{ml}$ (R\&D) for IL-17A, $30 \mathrm{pg} / \mathrm{ml}$ for IL-17A/F, $24 \mathrm{pg} / \mathrm{ml}$ (Abnova) and $10 \mathrm{pg} / \mathrm{ml}$ (Abcam) for IL-17B, $16 \mathrm{pg} / \mathrm{ml}$ for IL-17F, and $8 \mathrm{pg} / \mathrm{ml}$ for CXCL8.

\section{Reverse Transcription Quantitative Real-Time PCR (RT-qPCR)}

Total RNA was extracted from neutrophils by the RNeasy Mini Kit (Qiagen, Venlo, Limburg, Netherlands), as previously detailed (62). To completely remove any possible contaminating DNA, an on-column DNase digestion with the RNase-free DNase set (Qiagen) was performed during total RNA isolation. Total RNA was then reverse-transcribed into cDNA using Superscript III (Life Technologies, Carlsbad, CA, USA) and random hexamer primers (Life Technologies), while qPCR was carried out using Fast SYBR ${ }^{\circledR}$ Green Master Mix (Life Technologies). Sequences of gene-specific primer pairs (Life Technologies) are listed in Table S1 in Supplementary Material. Data were calculated by Q-Gene software $^{1}$ and expressed as mean normalized expression units after GAPDH normalization (63).

\section{Immunoblotting Experiments}

Total neutrophil proteins were recovered from protein-rich flowthrough solutions after the first centrifugation step of the RNeasy mini kit (Qiagen) procedure used for total RNA extraction, as previously described (62). Protein-rich flow-through from neutrophils were then immunoblotted by standard procedures using the anti-human IL-17A (AF-317-NA) and IL-17B (AF1248) goat IgG pAbs from R\&D Systems; anti-human phospho-STAT3 (Tyr705) rabbit pAbs (\#9131, Cell Signaling, Beverly, MA, USA); anti-human STAT3 rabbit pAbs (sc-482, Santa Cruz Biotechnology, Dallas, TX, USA), and anti-human $\beta$-actin mAbs (A5060 from Sigma). Blotted proteins were detected by using the Odyssey infrared imaging system (LI-COR Biosciences, Lincoln, NE, USA) (62).

\section{ChIP Assays}

Chromatin immunoprecipitation experiments were performed exactly as previously described (62). Briefly, nuclear extracts from $2 \times 10^{6}$ neutrophils or Th17 cell lines were immunoprecipitated using $1 \mu \mathrm{l}$ anti-H3K4me1 (ab8895) and anti-H3K27Ac (ab4729) pAbs (both from Abcam, Cambridge, United Kingdom). Coimmunoprecipitated material was subjected to qPCR analysis using the specific promoter primers (purchased from Life Technologies) listed in Table S2 in Supplementary Material. Data from qPCR were expressed as percentage over input DNA and are displayed as mean \pm SEM.

\section{ChIP-seq}

Purified DNA from H3K27Ac and H3K4mel ChIP assays (performed as described in the previous paragraph) was adapterligated and PCR-amplified for sequencing on HiSeq2000 platform (Illumina, Cambridge, UK) using TruSeq DNA Library Prep Kit (Illumina). After sequencing, reads were quality-filtered according

${ }^{1}$ http://www.gene-quantification.de/download.html (Accessed: February 10, 2018). to the Illumina pipeline. Single end (51 bp) reads were then mapped to the human genome (Genome Reference Consortium GRCh37, Feb/2009) using BOWTIE v1.0.0 (64). Only reads with no more than two mismatches (when compared to the reference genome) were converted to tag directories using HOMER's module known as "makeTagDirectory," and then converted to BedGraph format using HOMER's module known as "makeUCSCfile," to be finally normalized to $10^{7}$ total tag counts. ChIP-seq signals were visualized using Integrative Genomics Viewer. For H3K4me1 and H3K27Ac ChIP-seqs of Th17 cells, 36 bp reads, already filtered and mapped, were downloaded from database of the "roadmap epigenomics project"2 (NIH Epigenomics Roadmap Initiative). Aligned reads were then converted to BedGraph format and normalized to $10^{7}$ total tag counts.

\section{Gene Expression Data Set of Normal Hematopoietic Stem and Progenitor Cells}

Gene expression profiles of cells from normal bone marrow at different stages of human granulopoiesis were downloaded from Gene Expression Omnibus Database (GEO number: GSE42519) (65). Gene expression means and SEs were calculated from the values of the biological replicates present in the GEO database.

\section{Statistical Analysis}

Data are expressed as mean \pm SEM or mean \pm SD. Statistical evaluation was performed by using, depending on the experiment type, Student's $t$-test or two-way ANOVA followed by Bonferroni's post hoc test. $P$ values $<0.05$ were considered as statistically significant.

\section{Study Approval}

Human samples were obtained following informed written consent by both HDs and psoriatic patients. This study was carried out in accordance with the recommendations of Ethic Committee of the Azienda Ospedaliera Universitaria Integrata di Verona (Italy). All the experimental protocols were approved by the Ethic Committee and all subjects gave written informed consent in accordance with the Declaration of Helsinki.

\section{RESULTS}

\section{Human Neutrophils Incubated With a Variety of Agonists In Vitro Do Not Express IL-17 Members at Both mRNA and Protein Levels}

We have previously shown that human neutrophils (>99.7\% purity), incubated with $100 \mathrm{U} / \mathrm{ml} \mathrm{IFN \gamma}$ and/or $100 \mathrm{ng} / \mathrm{ml}$ ultrapure LPS for up to $20 \mathrm{~h}$ in vitro, do not produce IL-17A protein (12). Additional RT-qPCR experiments not only confirmed our previous data (Figure 1A) but also revealed that other agonists, including $5 \mu \mathrm{M}$ R848 and/or 1,000 U/ml IFN $\alpha$ (Figure 1B), $10 \mathrm{ng} / \mathrm{ml}$ GM-CSF, $100 \mathrm{nM}$ fMLF (Figure 1C),

${ }^{2}$ http://egg2.wustl.edu/roadmap/web_portal/processed_data.html (Accessed: February 10, 2018) 
1,000 U/ml G-CSF, and $5 \mathrm{ng} / \mathrm{ml}$ TNF $\alpha$ (Figure 1D), similarly fail to induce an accumulation of transcripts encoding IL-17A (Figures 1A-D, left panels), IL-17F (Figures 1A-D, middle panels), IL-17B, IL-17C, IL-17D, and IL-17E (data not shown) in neutrophils. LPS and/or IFN $\gamma, \mathrm{R} 848$ and/or IFN $\alpha$, GM-CSF or fMLF, however, were found to modulate the expression of CXCL8 mRNA (Figures 1A-C, right panels), while G-CSF or
TNF $\alpha$ modulated that of IL-1 ra mRNA (Figure 1D, right panel), as expected $(62,66,67)$. Consistent with the gene expression data, neither IL-17A, IL-17F (Table 1) nor IL-17A/F and IL-17B (data not shown) proteins could be detected in supernatants harvested from neutrophils incubated for $20 \mathrm{~h}$ with the stimuli used for the experiments shown in Figure 1, as well as with $500 \mu \mathrm{g} / \mathrm{ml} \beta$-glucan, $500 \mu \mathrm{g} / \mathrm{ml}$ curdlan, $1 \mu \mathrm{g} / \mathrm{ml}$ Pam3CSK4,
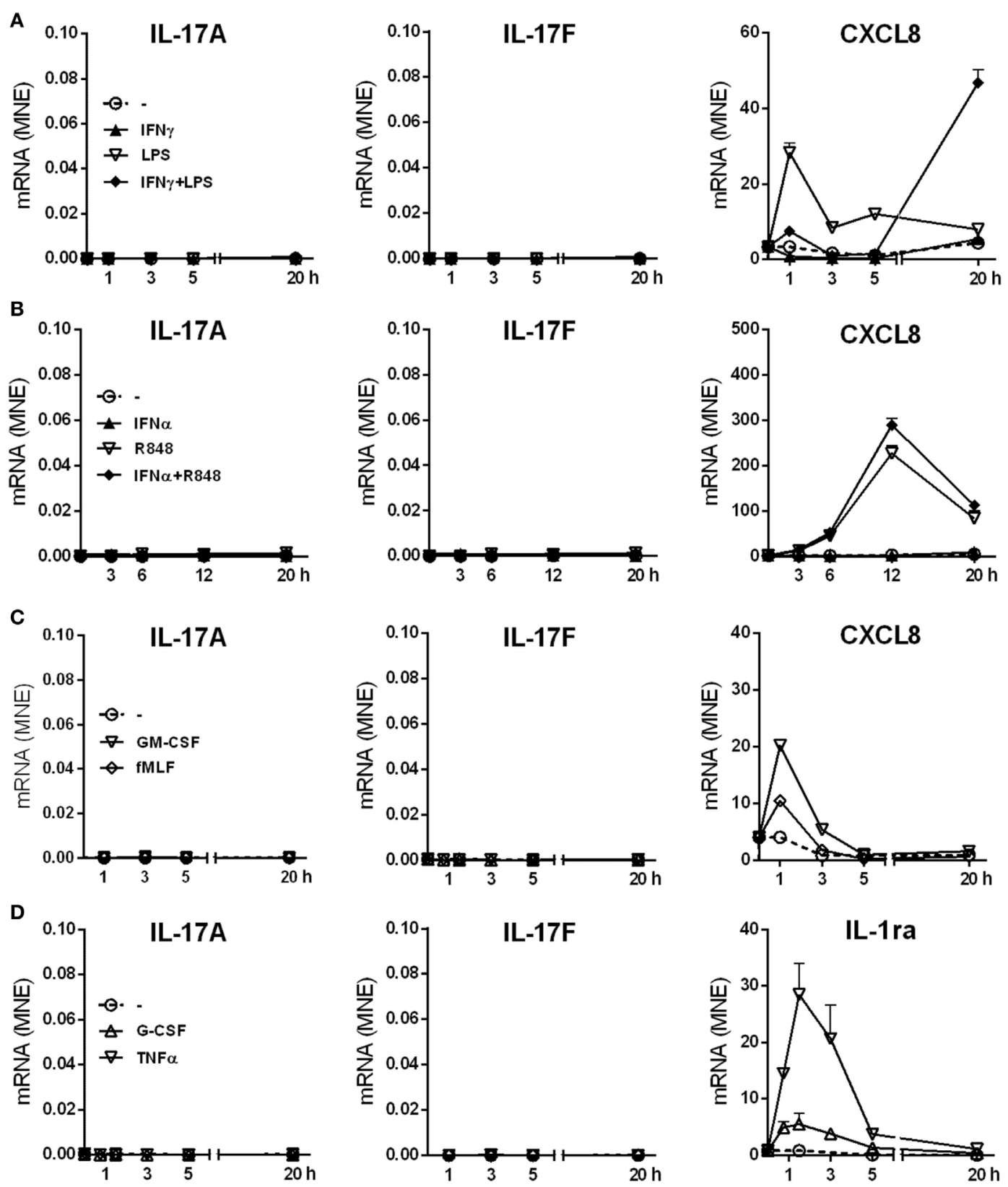

FIGURE 1 | IL-17A, IL-17F, CXCL8, and IL-1ra mRNA expression levels in human neutrophils activated by a variety of stimuli. Human neutrophils were cultured

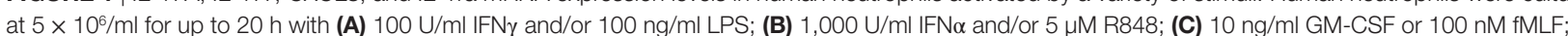
(D) $1,000 \mathrm{U} / \mathrm{ml}$ G-CSF or $5 \mathrm{ng} / \mathrm{ml}$ TNF $\alpha$. IL-17A, IL-17F, CXCL8, and IL-1ra mRNA expression was evaluated by reverse transcription quantitative real-time PCR (RT-qPCR) and data depicted as mean normalized expression (MNE) units after GAPDH mRNA normalization. The experiments depicted in each panels (A-D) are representative of at least three ones with similar results. Error bars stand for SEs calculated from triplicate qPCR reactions. 
$50 \mu \mathrm{g} / \mathrm{ml}$ poly(IC), and $100 \mu \mathrm{g} / \mathrm{ml}$ CpG ODN. Noteworthy, we used ELISA kits from two different commercial sources (see Materials and Methods) for either IL-17A or IL-17B, in both cases giving equivalent information. On the other hand, stimulus-dependent levels of CXCL8 could be measured in supernatants from our stimulated neutrophils, indicating that agonists were effective and cells fully responsive (Table 1). In any case, validity of both IL-17 primers and ELISA kits was demonstrated by the detection of either IL-17A, IL-17D, IL-17E, and IL-17F transcripts in human Th17, but not Th1, cell lines (Figure S1 in Supplementary Material), or IL-17A and IL-17F proteins in supernatants from $\mathrm{CD}^{+} \mathrm{T}$ cells activated with anti-CD3/anti-CD28 mAbs (Table 1). We could also detect intracellular IL-17B in lysates of human cerebral cortex (data not shown), as expected (68).

In other experiments, neutrophils were incubated for $3 \mathrm{~h}$ with $20 \mu \mathrm{g} / \mathrm{ml} \mathrm{IL}-6$ plus $2 \mu \mathrm{g} / \mathrm{ml} \mathrm{IL-23,} \mathrm{in} \mathrm{the} \mathrm{presence} \mathrm{or} \mathrm{the} \mathrm{absence}$ of inactivated conidia, or hyphae, from A. fumigatus. These experiments were done with the purpose to mimic, as much as possible, recently described experimental conditions shown to induce not only IL-17A and IL-17F but also IL-17RC, mRNA expression $(23,24,29,39,40,44)$. Neutrophils were also incubated with $100-500 \mathrm{ng} / \mathrm{ml} \mathrm{IL-17A}$ to reinvestigate (12) whether they respond to IL-17A or not. As shown in Figure 2, neutrophils treated with either IL-17A or IL-6 plus IL-23 (in the presence or the absence of inactivated A. fumigatus conidia/hyphae), showed neither induction of IL-17A (Figure 2A), IL-17F (Figure 2B), and IL-17RC (Figure 2C) mRNAs nor upregulation of the constitutively expressed IL-17RA transcript levels (Figure 2D). Similar results were obtained when incubation was prolonged up

TABLE 1 | Lack of IL-17A and IL-17F production by activated human neutrophils.

\begin{tabular}{|c|c|c|c|}
\hline Stimuli & IL-17A (pg/ml) & IL-17F (pg/ml) & CXCL8 (ng/ml) \\
\hline \multicolumn{4}{|l|}{ Neutrophils } \\
\hline- & nd & nd & $0.07 \pm 0.05$ \\
\hline $500 \mu \mathrm{g} / \mathrm{ml} \beta$-glucan & nd & nd & $0.41 \pm 0.16^{*}$ \\
\hline $500 \mu \mathrm{g} / \mathrm{ml}$ curdlan & nd & nd & $0.49 \pm 0.02^{\star \star \star}$ \\
\hline 10 ng/ml GM-CSF & nd & nd & $0.30 \pm 0.13^{*}$ \\
\hline $100 \mathrm{nM} f \mathrm{fMF}$ & nd & nd & $0.33 \pm 0.12^{*}$ \\
\hline $5 \mathrm{ng} / \mathrm{ml} \mathrm{TNF} \alpha$ & nd & nd & $1.22 \pm 0.90$ \\
\hline $1 \mu \mathrm{g} / \mathrm{ml}$ Pam3Cys & nd & nd & $10.31 \pm 3.85^{\star \star}$ \\
\hline 50 g/ml poly(l:C) & nd & nd & $0.02 \pm 0.02$ \\
\hline 100 ng/ml LPS & nd & nd & $0.89 \pm 0.22^{\star \star}$ \\
\hline $5 \mu \mathrm{M}$ R848 & nd & nd & $9.47 \pm 3.35^{\star \star}$ \\
\hline $100 \mu \mathrm{g} / \mathrm{ml}$ CpG ODN & nd & nd & $5.57 \pm 1.1^{\star \star \star}$ \\
\hline $100 \mathrm{U} / \mathrm{ml} \mathrm{IFN} \gamma$ & nd & nd & $0.10 \pm 0.04$ \\
\hline $\begin{array}{l}100 \mathrm{U} / \mathrm{ml} \mathrm{IFN} \gamma+100 \mathrm{ng} / \\
\mathrm{ml} \text { LPS }\end{array}$ & nd & nd & $2.51 \pm 1.1^{\star \star}$ \\
\hline \multicolumn{4}{|l|}{$\mathrm{CD4}^{+} \mathrm{T}$ cells } \\
\hline- & nd & nd & $2.51 \pm 1.1$ \\
\hline $5 \mu \mathrm{g} / \mathrm{ml}$ anti-CD3/CD28 & $739.6 \pm 56.6^{\star \star \star}$ & $948.9 \pm 95.4^{\star \star \star}$ & $172.6 \pm 25.1^{\text {*** }}$ \\
\hline
\end{tabular}

Human neutrophils $\left(5 \times 10^{6} / \mathrm{ml}\right)$ were cultured for $20 \mathrm{~h}$ with the indicated stimuli. $\mathrm{CD} 4^{+}$ $T$ cells were stimulated for up to $72 h$ with anti-CD3 and anti-CD28 mAbs. Cell-free supernatants were then harvested and IL-17A, IL-17F, and CXCL8 content measured by specific ELISA. Values represent the mean $\pm S D(n=3)$.

Asterisks stand for significant increases as compared to untreated cells: ${ }^{*} P<0.05$,

${ }^{* *} P<0.01,{ }^{* * *} P<0.001$, by Student's $t$-test.

nd, not detected; ODN, oligodeoxynucleotides. to $6 \mathrm{~h}$ (data not shown), or when neutrophils were stimulated with PMA/ionomycin after pretreatment for $1 \mathrm{~h}$ with IL-6 plus IL-23 (Figure S2 in Supplementary Material). Elevated levels of IL-17RC mRNAs were, however, detected in HBECs (data not shown), used as control cells (12), thus confirming that our primers were correctly designed. Importantly, the capacity of IL-6 plus IL-23 to stimulate neutrophils was evidenced by their ability to time-dependently promote STAT3 phosphorylation (Figure 2E), as well as to upregulate SOCS3 mRNA expression (Figure 2F), such an effect being potentiated by inactivated $A$. fumigatus conidia/hyphae (Figure 2F). By contrast, IL-17A-treatment influenced neither SOCS3 (Figure 2F) nor CXCL8 (data not shown) mRNA levels in neutrophils. Furthermore, no IL-17A (Figure 3A), IL-17F, or IL-17AF (data not shown) proteins were detected by ELISA either intracellularly or in supernatants harvested from neutrophils incubated with IL-6 plus IL-23, in the presence or the absence of inactivated A. fumigatus conidia/ hyphae. Under the same experimental conditions, CXCL8 protein was newly synthesized and released by neutrophils incubated with IL-6 plus IL-23 in the presence of inactivated A. fumigatus conidia/hyphae, but not in their absence (Figure 3B). Finally, no IL-17A was detected in IL-6 plus IL-23-stimulated neutrophils by intracellular staining experiments (data not shown), using the anti-human IL-17A eBio64DEC17 mouse IgG1 (from eBioscience) previously shown to function under identical experimental conditions by Taylor et al. (39). We have no clues explaining why we did not reproduce the positive effects on IL-17 expression by IL-6 plus IL-23 $(23,24,29,39,40)$, with or without inactivated A. fumigatus conidia/hyphae. One possibility is that the hyphal extracts from A. fumigatus used by Taylor and colleagues (39), but not our inactivated conidia/hyphae, contain some undefined PAMP(s) that effectively promote(s) IL-17A production/IL-17RC expression by human neutrophils.

Taken together, our data extend previous findings on the inability of human neutrophils to express IL-17 members at the mRNA and protein levels under various activating conditions (13-16). Data also confirm and extend our previous findings (12) on the inability of IL-17A to directly modify IL-17A, IL-17F, IL-17RA, IL-17RC, SOCS3, and CXCL8 gene expression in human neutrophils.

\section{Human Neutrophils Incubated With IL-6 Plus IL-23, in the Presence or the Absence of Inactivated A. fumigatus Hyphae/ Conidia, Do Not Express IL-17RC}

Flow cyometry experiments confirmed (12) that neutrophils, either freshly isolated, or incubated for $3 \mathrm{~h}$ in the absence, or the presence of IFN $\gamma$ plus LPS (Figure 4A), display only surface IL-17RA, but not IL-17RC. No IL-17RC surface levels were also observed in neutrophils incubated with either R848 (Figure 4A), or IL-6 plus IL-23, in the latter case in the absence, or in the presence of either inactivated A. fumigatus conidia/ hyphae, or IL-17A (Figure 4B). IL-17RA surface levels were downregulated in neutrophils treated with IFN $\gamma$ plus LPS, R848 (Figure 4A) and IL-6 plus IL-23 with IL-17A (Figure 4B). In these experiments, HBEC were, again, used as positive control 

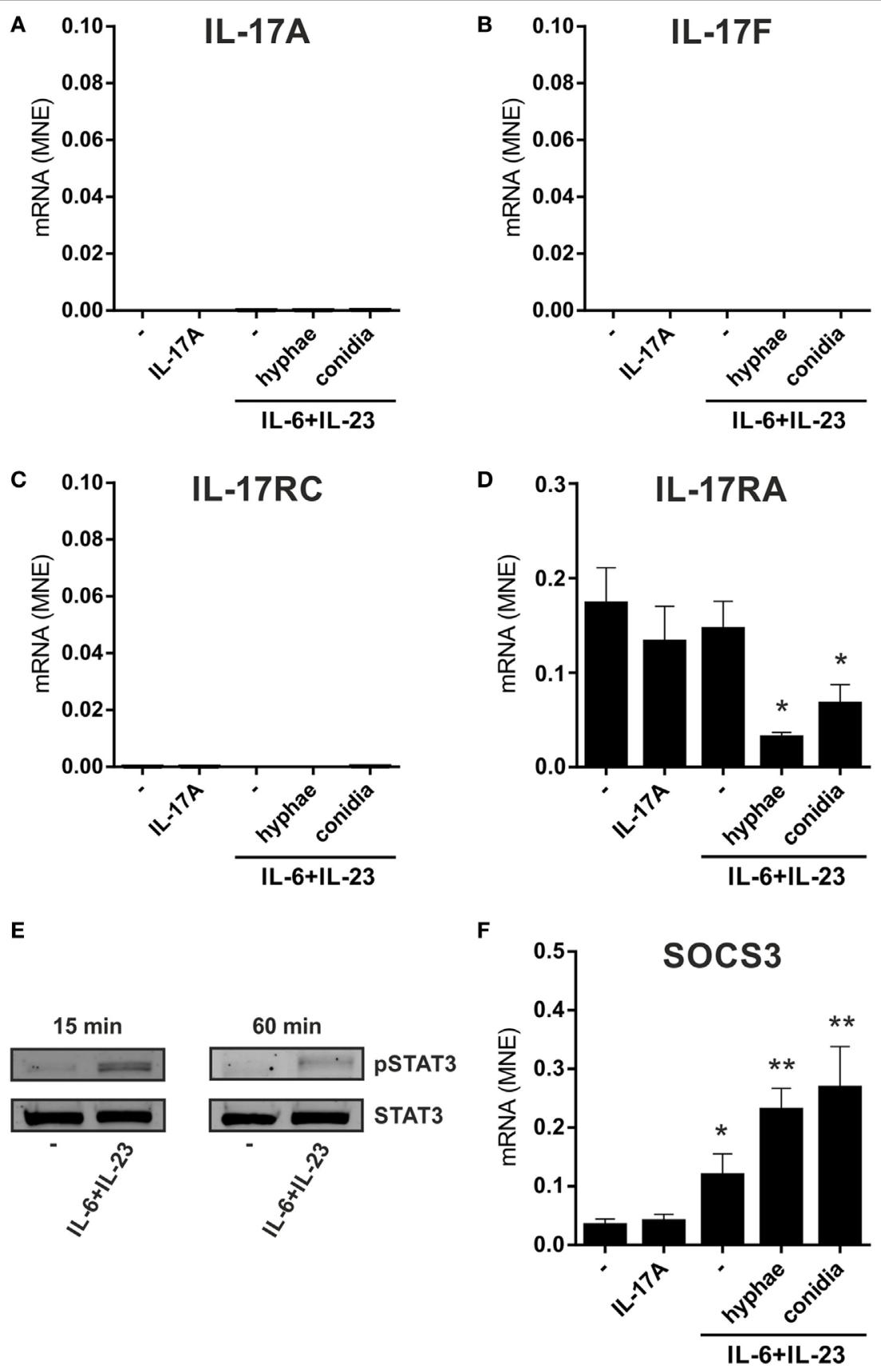

FIGURE 2 | No induction of IL-17A, IL-17F, and IL-17RC mRNA expression in neutrophils incubated with IL-6 plus IL-23, in combination with inactivated Aspergillus fumigatus hyphae or conidia. Neutrophils $\left(5 \times 10^{6} / \mathrm{ml}\right)$ were incubated either with $100 \mathrm{ng} / \mathrm{ml} \mathrm{rlL}-17 \mathrm{~A}$ for $2 \mathrm{~h}$ or with or without $20 \mathrm{\mu g} / \mathrm{ml} \mathrm{IL}-6 \mathrm{plus} 2 \mu \mathrm{g} / \mathrm{ml} \mathrm{IL}-23 \mathrm{for}$ $1 \mathrm{~h}$, prior to adding, or not, inactivated $A$. fumigatus conidia (1:5 neutrophils/conidia ratio) and hyphae (1:1 neutrophils/hyphae ratio) for additional $1 \mathrm{~h}$. Neutrophils were then harvested for RNA extraction to evaluate IL-17A (A), IL-17F (B), IL-17RC (C), IL-17RA (D), and SOCS3 (F) mRNA expression by reverse transcription quantitative real-time PCR. Gene expression data are depicted as mean normalized expression (MNE) units after GAPDH mRNA normalization (mean \pm SEM, $n=4$ ). Asterisks stand for significant differences as compared to untreated cells: ${ }^{\star} P<0.05,{ }^{\star \star} P<0.01$, by Student's $t$-test. (E) Immunoblot displaying STAT3 tyrosine phosphorylation in neutrophils, either untreated or cultured for 15 or 60 min with $20 \mu \mathrm{g} / \mathrm{ml} \mathrm{IL}-6$ plus $2 \mu \mathrm{g} / \mathrm{ml} \mathrm{IL}-23$ (representative experiment, $n=2$ ).

for both IL-17RA and IL-17RC surface expression (data not shown) (12). It should be pointed out that, for the investigation of surface IL-17RC, we have been using the same antiIL-17RC, directly PE-conjugated, Abs used in Taylor et al.'s study (39), other than the anti-IL-17RC biotin-conjugated Abs that necessitate PE-conjugated streptavidin for detection (12), without noticing any difference between them. By the way, IFN $\gamma$ plus LPS and R848 (Figure S3A in Supplementary Material), as well as IL-6 plus IL-23 in the presence of inactivated A. fumigatus conidia/hyphae (Figure S3B in Supplementary Material), 

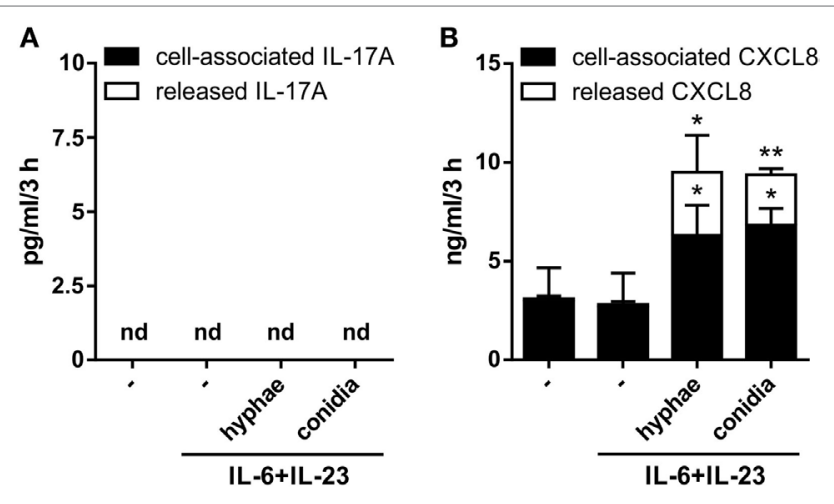

FIGURE 3 | Lack of IL-17A and IL-17F production by human neutrophils activated by IL-6 plus IL-23 in combination with inactivated Aspergillus fumigatus hyphae or conidia. Neutrophils $\left(5 \times 10^{6} / \mathrm{ml}\right)$ were incubated with or without $20 \mu \mathrm{g} / \mathrm{ml} \mathrm{IL-6}$ plus $2 \mu \mathrm{g} / \mathrm{ml} \mathrm{IL}-23$ and then cultured for three more hours in the presence or not of inactivated $A$. fumigatus conidia and hyphae (used at 1:5 and 1:1, respectively). After incubation, IL-17A (A) and CXCL8 (B) levels were determined in cell-free supernatants and in corresponding cell pellets by specific ELISA. Values are depicted as the mean \pm SD or as not detected (nd) when values were under the detection limit $(n=3)$. Asterisks stand for significant differences as compared to untreated cells: ${ }^{\star} P<0.05$, ${ }^{\star \star} P<0.01$, by Student's $t$-test.

variably modulated both CD11b and CD62L expression. All in all, data illustrate that IL-6 plus IL-23, regardless of their combination with inactivated $A$. fumigatus conidia/hyphae, and despite their capacity to upregulate SOCS3 mRNA expression (Figure 2F), do not induce the expression of IL-17RC in our hands, contradicting some studies $(39,44)$.

\section{$\mathrm{O}_{2}^{-}$Production by Neutrophils Stimulated With Inactivated $A$. fumigatus Hyphae After Preincubation With IL-6 plus IL-23 Is Not Modified by Either Exogenous IL-17A or IL-17A Inhibitors}

We then measured the capacity to release $\mathrm{O}_{2}^{-}$by neutrophils preincubated with or without IL-6 plus IL-23 for $1 \mathrm{~h}$, and then treated for one additional hour with inactivated A. fumigatus hyphae, in the presence or the absence of either IL-17A or anti-IL-17A neutralizing Abs (Figure S4 in Supplementary Material). As control, neutrophils were also stimulated with either inactivated A. fumigatus hyphae alone or $20 \mathrm{ng} / \mathrm{ml}$ PMA. As shown in Figure S4 in Supplementary Material, inactivated A. fumigatus hyphae were found to trigger a remarkable $\mathrm{O}_{2}^{-}$ production by neutrophils, even though lower than PMA. However, A. fumigatus hyphae-stimulated $\mathrm{O}_{2}^{-}$release was not potentiated by the preincubation of neutrophils with IL-6 plus IL-23 (which, by themselves, did not trigger any $\mathrm{O}_{2}^{-}$production) (Figure S4 in Supplementary Material). Under the latter experimental conditions, addition of either IL-17A or antiIL-17A neutralizing Abs ( $\alpha$ IL-17A Abs) did not influence the effect of inactivated A. fumigatus hyphae on neutrophil-derived $\mathrm{O}_{2}^{-}$(Figure S4 in Supplementary Material), supporting the lack of induction of surface IL-17RC expression and endogenous IL-17A, respectively.

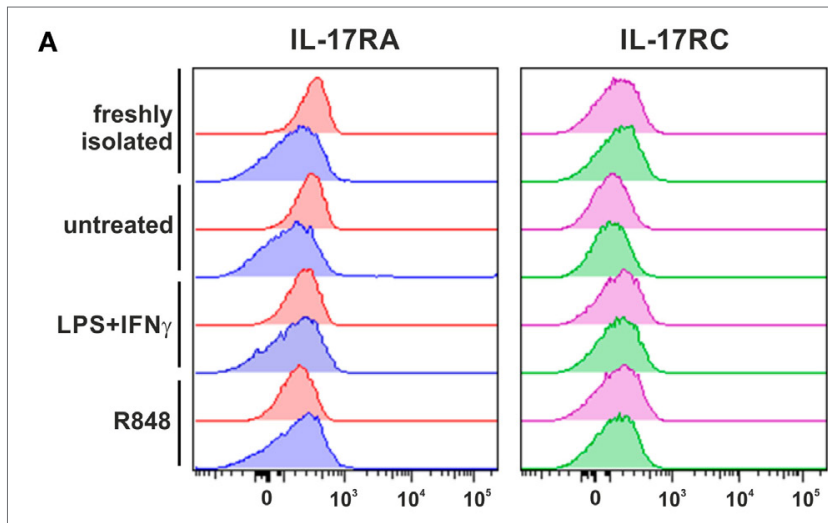

$\mathbf{B}$

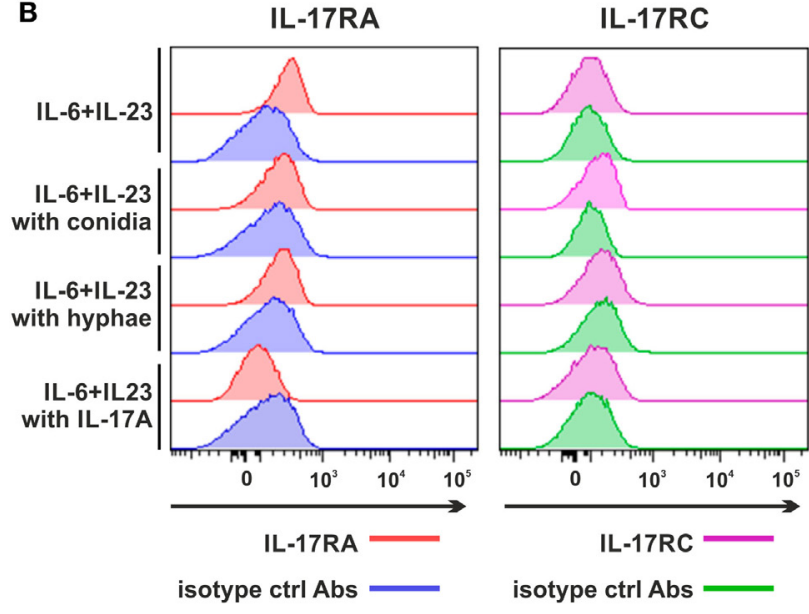

FIGURE 4 | Expression of surface IL-17RA and IL-17RC in neutrophils activated under various experimental conditions. Expression of surface IL-17RA (left panel) and IL-17RC (right panel) was evaluated by flow cytometry in neutrophils either freshly isolated or cultured for $3 \mathrm{~h}$ without or with $100 \mathrm{U} / \mathrm{ml}$ IFN $\gamma$ plus $100 \mathrm{ng} / \mathrm{ml}$ LPS, $5 \mu \mathrm{M}$ R848 (A), $20 \mu \mathrm{g} / \mathrm{ml} \mathrm{IL}-6$ plus $2 \mathrm{\mu g} / \mathrm{ml} \mathrm{IL-23}$ alone or in the presence of inactivated Aspergillus fumigatus conidia, hyphae or 500 ng/ml rlL-17A (B). Graphs depict a representative experiment out of three independent ones with similar results. Histograms show staining by specific and isotype control Abs, respectively, for each stimulatory condition.

\section{Chromatin Organization at the IL-17A and IL-17F Genomic Loci of Human Neutrophils}

Signatures of histone posttranslational modifications at a specific gene locus provide indicative elements to predict whether such a gene can be transcribed or not $(69,70)$. Therefore, we evaluated the presence of histone marks associated to active (e.g., H3K27Ac) and poised (e.g., H3K4me1) genomic regulatory elements (71) at the $I L 17 A$ and $I L 17 F$ loci of human neutrophils. Genome-wide ChIP-seq assays demonstrated that, in freshly isolated neutrophils, the entire genomic region containing IL17A and IL17F loci is completely devoid of H3K27Ac and H3K4me1 (Figure 5). By contrast, based on data available from the NIH Epigenomics Roadmap Initiative (72), multiple $\mathrm{H} 3 \mathrm{~K} 4 \mathrm{me} 1$ peaks are present in the same genomic regions of PMA/ionomcyin-stimulated Th17 cells, while H3K27Ac peaks 
localize at the IL17A locus only (Figure 5). To validate the previous data, we performed $\mathrm{H} 3 \mathrm{~K} 27 \mathrm{Ac}$ and $\mathrm{H} 3 \mathrm{~K} 4 \mathrm{me} 1 \mathrm{qPCR}$ ChIPs using neutrophils incubated for $1 \mathrm{~h}$ either with or without $20 \mu \mathrm{g} / \mathrm{ml}$ IL- 6 plus $2 \mu \mathrm{g} / \mathrm{ml}$ IL-23, as well as Th17 cell lines (in which IL-17A and IL-17F mRNA is constitutively transcribed), used as positive controls (Figure 6). Based on the H3K4me1 peaks from the ChIP-seqs of Th17 cell lines (72) (Figure 5), we designed specific primers amplifying potential regulatory regions at the $I L 17 A$ and $I L 17 F$ genomic loci, namely IL-17A\# 1 and IL-17F\# 1 for enhancers, and IL-17A\#2, IL-17A\#3, and IL-17F\#2 for promoters (Figures 6A,B). As expected, Th17 cell lines displayed constitutively bound H3K4me1 at their IL-17A and IL-17F promoters and enhancers (Figures 6A,B, left panels). We also detected high levels of $\mathrm{H} 3 \mathrm{~K} 27 \mathrm{Ac}$ at the IL-17A and IL-17F promoters and enhancers of Th17 cell lines (Figures 6A,B, right panels), in line with their constitutive expression of both IL-17A and IL-17F mRNA (data not shown). By contrast, we did not observe any H3K4me1 or $\mathrm{H} 3 \mathrm{~K} 27 \mathrm{Ac}$ at the IL17A and IL17F loci of neutrophils, either under resting conditions (thus confirming the ChIP-seq data shown in Figure 5) or after incubation with IL-6 plus IL-23 (Figures 6A,B). In fact, the H3K4mel and H3K27Ac levels at the IL-17A and IL-17F enhancers in neutrophils were similar to those ones present at the PRL promoter, a genomic region with a closed chromatin conformation in myeloid cells, herein used to determine the signal background (Figures 6A,B). Notably, measurable amounts of $\mathrm{H} 3 \mathrm{~K} 4 \mathrm{me} 1$ and $\mathrm{H} 3 \mathrm{~K} 27 \mathrm{Ac}$ were found at the SOCS3 promoter of neutrophils under resting conditions, as well as in Th17 cell lines (Figure 6C). Interestingly, H3K27Ac levels tended to increase in neutrophils incubated with IL-6 plus IL-23 (Figure 6C), in accordance with a supposed STAT3dependent induction of SOCS3 mRNA (73). Taken together, data indicate that the organization of the IL17A and IL17F loci in human neutrophils is characterized by the absence of poised chromatin marks, unlike that of IL-17A- and IL-17F-producing Th17 cell lines. Data also indicate that human neutrophils do not reorganize the chromatin of the $I L 17 A$ and $I L 17 F$ loci in response to IL-6 plus IL-23, consistent with their inability to de novo accumulate IL-17A and IL-17F mRNA.

\section{Human Neutrophils From Patients With Psoriasis Do Not Express IL-17A and/or IL-17F mRNA}

We subsequently investigated whether neutrophils isolated from patients with active psoriasis could express/produce IL-17A, IL-17F, and/or IL-17RC mRNA, either constitutively or upon incubation for $20 \mathrm{~h}$ with IFN $\gamma$ plus LPS, R848, or IL-17A. As shown in Figure 7A, the latter was not the case, as psoriatic neutrophils behaved similarly to neutrophils from HDs. Psoriatic neutrophils did not also respond to IL-17A (Figure 7A), due to their lack of surface IL-17RC expression (Figure 7B). Nonetheless, psoriatic neutrophils fully responded to either R848 or IFN $\gamma$ plus LPS, as they accumulated CXCL8, TNF $\alpha$, and SOCS3 transcripts at levels comparable to those in HD neutrophils (Figure 7A).

\section{Commercial Anti-IL-17A Abs (AF-317-NA) Positively Stain Cytospins of Resting and Activated Neutrophils due to Their Non- Specific Recognition of Neutrophil Intracellular Proteins Different From IL-17A}

In additional experiments, cytospin slides of resting and R848stimulated neutrophils were incubated with goat anti-human IL-17A AF-317-NA Abs, previously shown to stain neutrophils in pathological tissues $(18-22,25,27,28,30-33,35,36,41-43,45$, 47-50), as also confirmed by our IHC/IF staining of inflamed psoriatic tissue (Figure 8A). Consistently, neutrophil cytospin slides became strongly positive upon incubation with AF-317-NA, yet with no difference between resting or R848-activated neutrophils (Figure 8B). By contrast, immunostaining of the same cytospins slides with anti-human CXCL8 Abs showed a strong positivity only in R848-treated neutrophils (Figure 8B), thus excluding methodological artifacts. Not surprisingly, neutrophils from the same experiments were found totally negative for both IL-17A mRNA expression and IL-17A production once processed for RT-qPCR analysis and ELISA. The detection of IL-17A-positive neutrophils by IHC, in the absence of IL-17A mRNA, could

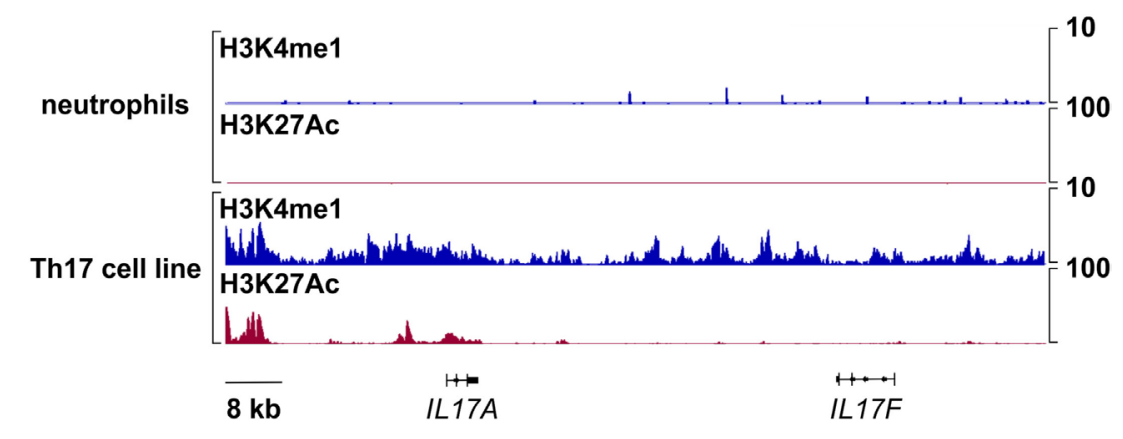

FIGURE 5 | Chromatin immunoprecipitation (ChIP)-Seq profiles of H3K4me1 and H3K27Ac at the IL17A and IL17F loci in human neutrophils and Th17 cell lines. Representative snapshots depicting H3K4me1 and H3K27Ac ChIP-seqs at the IL17A and IL 17F genomic loci in freshly isolated human neutrophils or, as retrieved from NIH Epigenomics Roadmap Initiative (72), in phorbol mysistate acetate/ionomycin-stimulated Th17 cell lines. 
A

IL17A locus
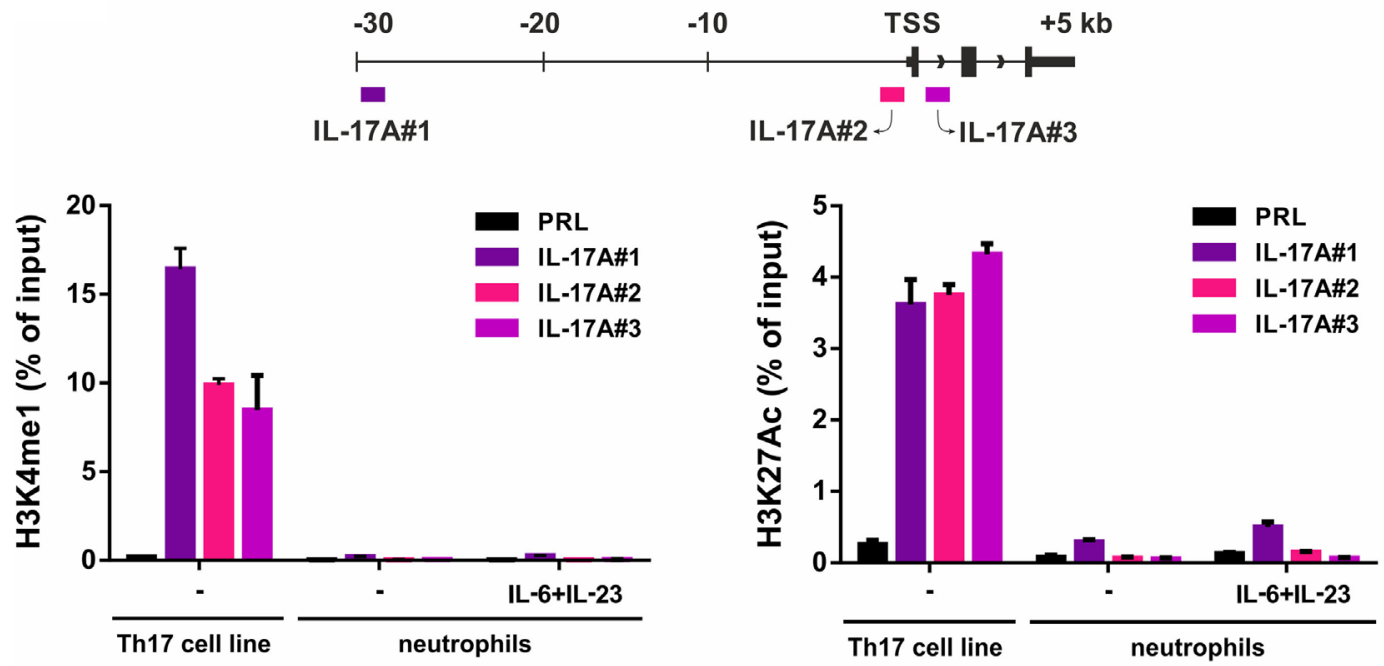

B

IL17F locus
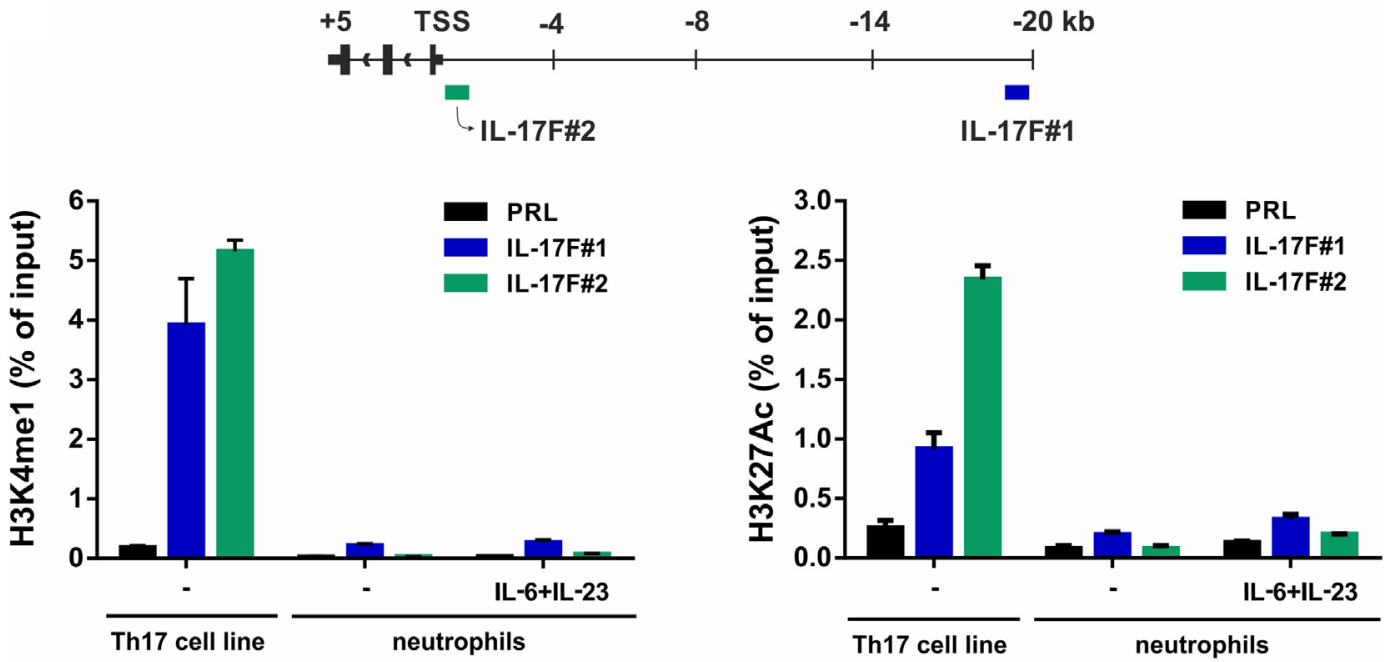

C
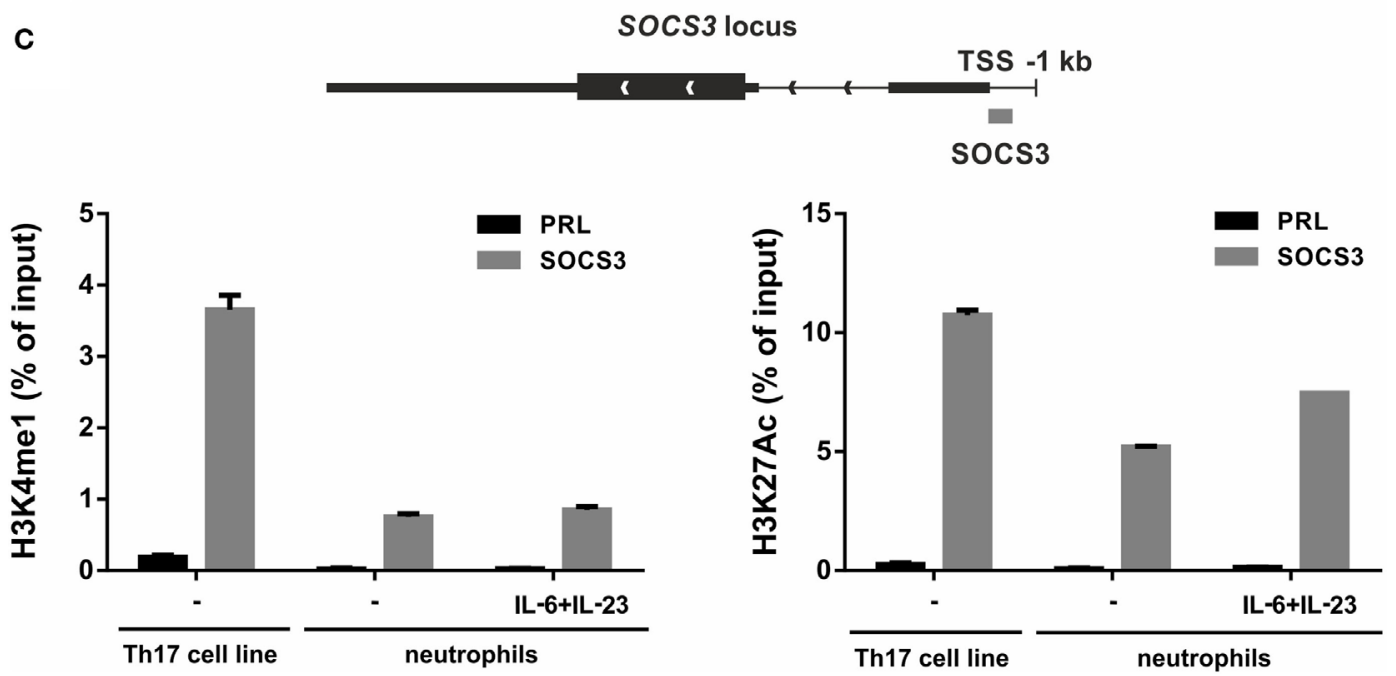

FIGURE 6 | Continued 
FIGURE 6 | H3K4me1 or H3K27Ac levels at the IL-17A, IL-17F, and SOCS3 genomic loci of Th17 cell lines and resting/L-6 plus IL-23-activated neutrophils. Enrichment levels of H3K4me1 (left panels) and H3K27Ac (right panels) at the IL-17A (A), IL-17F (B), and SOCS3 (C) genomic loci by chromatin immunoprecipitation (ChIP) analysis in human Th17 cell lines and neutrophils incubated for $1 \mathrm{~h}$ with or without $20 \mu \mathrm{g} / \mathrm{ml} \mathrm{IL}-6 \mathrm{plus} 2 \mu \mathrm{g} / \mathrm{ml} \mathrm{IL}-23$. (A-C) Schemes illustrating the positions of the designed primer pairs amplifying promoter and potential enhancer regions of IL-17A, IL-17F, and SOCS3 for ChIP analysis are depicted at the top of each panel. Coimmunoprecipitated DNA samples were expressed as percent of the total input. Panels in (A-C) depict a representative experiment out of two independent ones with similar results. Error bars represent SEs calculated from triplicate qPCR reactions.

be explained by the fact that the cytokine may be synthesized in bone marrow neutrophil precursors, at stages during which granule proteins, such as myeloperoxidase (MPO), elastase, and azurocidin 1, are formed (74). However, in transcriptomes made by Rapin et al., generated from cells isolated at different stages during granulopoiesis (65), we did not identify any IL-17A mRNA accumulation (Figure 9). In the same database, we not even detected IL-17RC and IL-10 mRNA (Figure 9), consistent with the inability of mature neutrophils to express them $(12,70)$. By contrast, we did find MPO, elastase, and azurocidin 1 mRNA expression only in transcriptomes of neutrophil precursors, as expected (74), thus validating the reliability of the database (65) (Figure 9). In any case, consistent with the absence of intracellular IL-17 (Figure 3A), immunoblots performed with AF-317-NA revealed that whole neutrophil lysates did not show any positive signal in correspondence of recombinant human IL-17A (rhIL17A) molecular weight (MW) (Figure 8C). In these experiments, neutrophils were either freshly isolated (D1 and D2 in Figure 8C), or cultured for $3 \mathrm{~h}$ with or without R848, $2 \mu \mathrm{g} / \mathrm{ml} \mathrm{IL-6}$ plus $0.2 \mu \mathrm{g} / \mathrm{ml}$ IL-23 (low IL-6 plus IL-23 in Figure 8C), or $20 \mu \mathrm{g} /$ $\mathrm{ml}$ IL-6 plus $2 \mu \mathrm{g} / \mathrm{ml}$ IL-23 (high IL-6 plus IL-23 in Figure 8C). By contrast, AF-317-NA strongly reacted in correspondence of neutrophil proteins displaying higher MW than that of rIL-17A, with no difference in signals among freshly isolated, stimulated, or untreated neutrophils (Figure 8C). While these data confirm the observations reported by Tamarozzi et al. (13), who also used mouse anti-IL-17A mAbs (\#41802, from R\&D) in addition to AF-317-NA, they are in contrast with Lin et al.s findings (30) illustrating a constitutive IL-17A (but not IL-17F) expression in neutrophil lysates, as revealed by immunoblotting with \#41802. Halwani et al. (23) too found constitutive IL-17A amounts in lysates of neutrophils from asthmatic patients, even increasing upon cell incubation with IL-21 and/or IL-23 for $18 \mathrm{~h}$, as revealed by immunoblotting with unspecified Abs from R\&D. However, since only portions of the immunoblots are shown in Halwani et al. (23) and Lin et al. (30) paper, it is not known whether additional proteins were recognized by Abs used. Whatever the case is, our experiments suggest that the positive staining of neutrophils detected by IHC and IF using AF-317-NA on cytospins and, possibly, tissue slides, stands for an IL-17A-unrelated binding(s) to neutrophils.

\section{Human Neutrophils Do Not Express/ Produce IL-17B}

In a separate set of experiments, we also tested goat anti-IL-17B (AF1248) Abs that, in recent publications, have been shown to positively stain, by IHC and IF, neutrophils present in tissue samples from RA (75) and colon carcinoma (CCR) (76) patients.
Consistently, we found that also neutrophils present in inflamed psoriatic tissue were strongly detectable by IHC and IF stainings with AF1248 (Figure 10A). On cytospin slides, AF1248 stained neutrophils isolated from the blood of HDs and incubated for $3 \mathrm{~h}$ with or without $5 \mu \mathrm{M}$ R848 in an equivalent manner (Figure 10B). However, by immunoblotting of whole lysates prepared from neutrophils treated with R848 or IL-6 plus IL-23, AF1248 did not recognize any protein corresponding to the rhIL-17B MW (Figure 10C). These negative observations were also confirmed by measurement of intracellular, as well as, released IL-17B by two commercial ELISA (see Materials and Methods). Accordingly, no antigenic IL-17B could be measured in supernatants and whole lysates from neutrophils incubated with $5 \mu \mathrm{M}$ R848 with

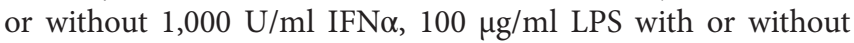
$100 \mathrm{U} / \mathrm{ml} \mathrm{IFN} \gamma, 2 / 20 \mu \mathrm{g} / \mathrm{ml}$ IL-6 plus $2 \mu \mathrm{g} / \mathrm{ml}$ IL-23 (data not shown), in agreement with the lack of IL-17B mRNA induction. Detectable IL-17B levels were, however, measured in lysates of human cerebral cortex (68), demonstrating that our two IL-17B ELISA kits were sensitive enough. Altogether, our data indicate that, similarly to the case of AF-317-NA, the positive stainings of neutrophils in cytospin slides and, possibly, tissue samples by AF1248, likely stand for an IL-17B-unrelated, non-specific, recognition occurring in human neutrophils.

\section{DISCUSSION}

In this study, we have reinvestigated in-depth whether human neutrophils produce IL-17A, IL-17B, IL-17F, and IL-17A/F in vitro. According to the literature, in fact, information on such an issue appears discordant, as the majority of papers sustain that human neutrophils do express/produce IL-17A (18-53), while a minority fail to detect it (12-17). This issue is even more critical if one takes into account that also the capacity of murine neutrophils to produce IL-17A, shown in a variety of mouse models of infectious and autoimmune inflammation $(24,39,40,77-81)$, has been recently questioned $(82,83)$. Preclinical models evidencing neutrophil-derived IL-17 as pathogenic in diseases might be, in fact, prematurely taken as proof-of-concept for immediate translational applications in humans.

Herein, by using multiple methodological approaches (RT-qPCR, ChIP, ChIP-seq, ELISA, intracellular staining, and immunoblotting), we confirm and greatly extend our previous findings (12) showing that highly purified ( $>99.7 \%$ ) populations of human neutrophils, either resting or activated by a variety of stimulatory conditions, including TLR and dectin ligands, fungal PAMPs and cytokines, used singly or in combinations, neither express IL-17A, IL-17F, IL-17B, IL-17C, IL-17D, and IL-17E mRNA nor produce IL-17A, IL-17F, IL-17A/F, and IL-17B in vitro. Similarly, we show that also neutrophils isolated from 

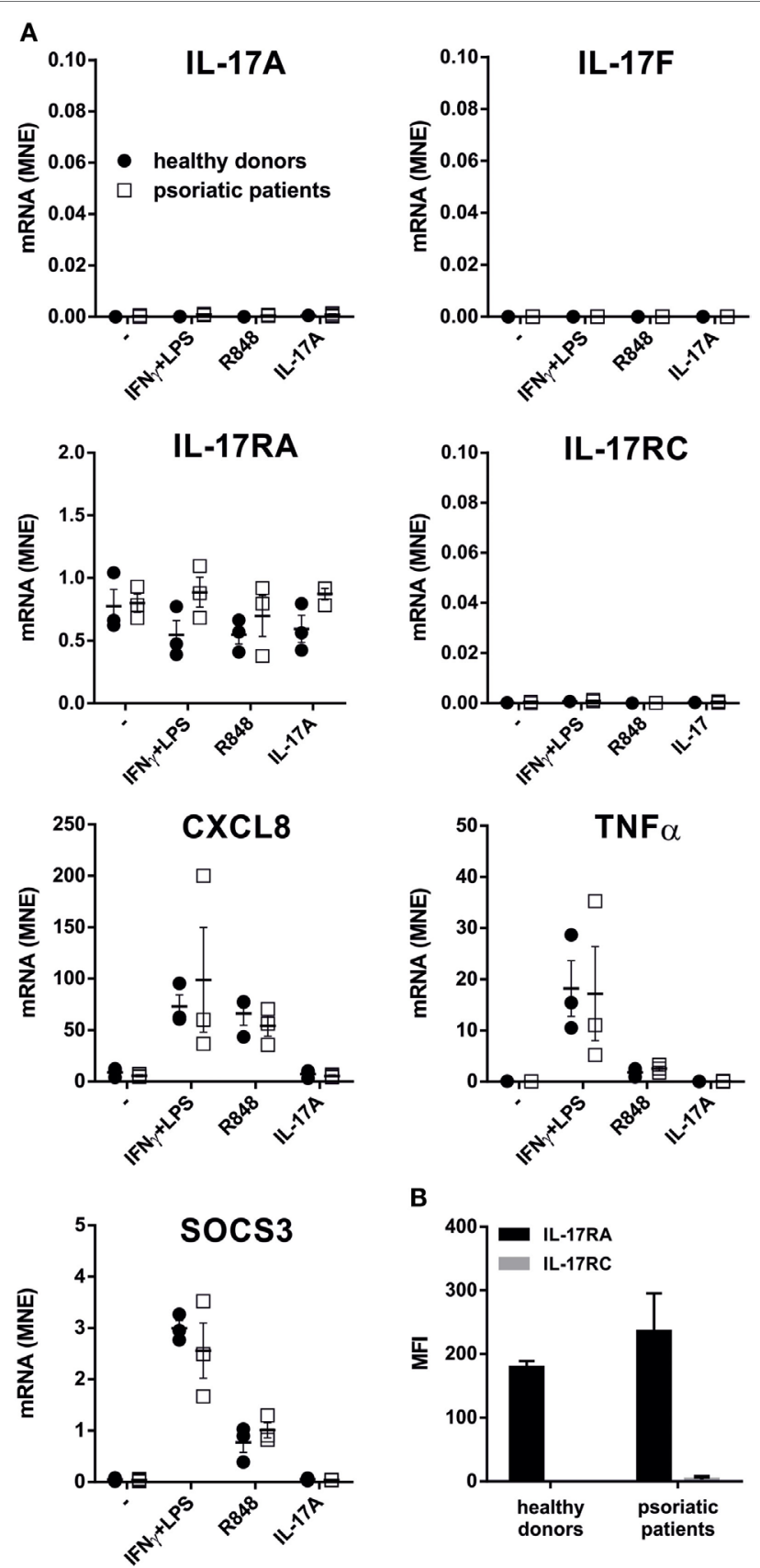

B

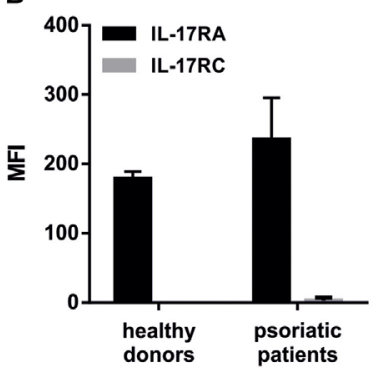

FIGURE 7 | IL-17A, IL-17F, IL-17RA, IL-17RC, CXCL8, TNF $\alpha$, and SOCS3 mRNA expression, as well as IL-17R surface expression, in neutrophils from patients with psoriasis. (A) Neutrophils isolated from healthy donors (HDs) $(n=3)$ or psoriatic patients $(n=3)$ were cultured for $20 \mathrm{~h}$ with $100 \mathrm{U} / \mathrm{ml} \mathrm{IFN \gamma}$ plus $100 \mathrm{ng} / \mathrm{ml}$ LPS, $5 \mu \mathrm{M}$ R848, or $500 \mathrm{ng} / \mathrm{ml} \mathrm{IL-17A} \mathrm{to} \mathrm{evaluate} \mathrm{IL-17A,}$ IL-17F, IL-17RA, IL-17RC, CXCL8, TNF $\alpha$, and SOCS3 mRNA expression by reverse transcription quantitative real-time PCR. Gene expression data are depicted as mean normalized expression (MNE) units after GAPDH mRNA normalization. (B) Surface IL-17RA and IL-17RC expression evaluated by flow cytometry in human neutrophils from HDs or psoriatic patients. Values represent the mean $\pm \operatorname{SEM}(n=3)$. For the data of panels $(\mathbf{A}, \mathbf{B})$ no significant differences between HDs or psoriatic patients were observed by two-way ANOVA followed by Bonferroni's post-test. patients with active psoriasis do not express IL-17F, IL-17B, IL-17C, IL-17D, and IL-17E as well as IL-17RC mRNA when activated by R848, IFN $\gamma$ plus LPS, and IL-17A in vitro. In such regard, RNA-Seq experiments made by Tamarozzi et al. (13), using neutrophils isolated by negative-selection ( $>99.9 \%$ pure) from HDs or RA patients (as we do), then treated for $1 \mathrm{~h}$ with a range of inflammatory cytokines (TNF $\alpha, \mathrm{GM}-\mathrm{CSF}, \mathrm{G}-\mathrm{CSF}$, IL-6, IL-1 $\beta$, CXCL8, IFN $\alpha$, and IFN $\gamma$ ), also failed to detect any of the mRNA for IL-17 cytokine family. By contrast, Yamanaka et al. (15) have been recently reported the presence of constitutive IL-17A transcripts in neutrophils from HDs and psoriasis patients isolated by density gradient cell separation ( $92 \%$ purity). However, when the same cell populations were further purified by magnetic sorting (reaching a $99 \%$ purity), they were found totally devoid of IL-17A mRNA (15), indicating that contaminating monocytes/lymphocytes were actually responsible for the IL-17A mRNA expression in unsorted "neutrophils." Needless to say that Yamanaka et al.s observations (15) are example of a notion that we have been always recommending in our studies $(56,59,84)$, namely the requirement of using highly purified cell populations if one wants to obtain correct results when examining neutrophil gene expression or neutrophil-derived cytokines.

Interestingly, other studies confirm that human neutrophils do not constitutively contain IL-17A transcripts (13, 24, 29, 30, $35,39,40,44)$, including those ultimately showing a concurrent positivity for IL-17A protein, as revealed by intracellular flow cytometry $(24,39,40)$, ELISA $(24,39)$, confocal microscopy (39), or IHC (29). Some authors $(30,35)$ speculated that the absence of IL-17A mRNA in mature neutrophils indicates that the cytokine is synthesized in bone marrow neutrophil precursors, at the stages when granule proteins are formed (74). However, we would exclude such a hypothesis, as our analysis of transcriptomes generated from all types of bone marrow cell populations (65) failed to identify an IL-17A mRNA accumulation at any stage of neutrophil maturation.

We were unable to detect IL-17A and IL-17F mRNA/production/release even by human neutrophils incubated with IL-6 plus IL-23, in contrast to what repeatedly found $(23,24,29$, $39,40)$. In our experiments, neutrophils did, however, respond to IL-6 plus IL-23 in terms of STAT3 phosphorylation and SOCS3 mRNA induction, indicating that the two cytokines are effectively stimulatory for neutrophils. It is intriguing that, apart from Halwani et al. (23), who found that either $20 \mathrm{ng} / \mathrm{ml} \mathrm{IL-6}$ or $20 \mathrm{ng} / \mathrm{ml}$ IL-23, singly used, directly induced IL-17A mRNA and protein in a fraction of neutrophils from asthmatic patients, other groups highlighted the necessity to use at least $20 \mu \mathrm{g} / \mathrm{ml}$ IL-6 plus $2 \mu \mathrm{g} / \mathrm{ml}$ IL-23 $(29,39,40)$ (as we did). In this context, the paper by $\mathrm{Hu}$ et al. (24), based on the use of neutralizing Abs and pharmacological inhibitors, identified endogenous IL-6 and IL-23 as indirect inducers of IL-17A expression in a fraction of neutrophils either infected with Mycobacterium tuberculosis (MTB), or stimulated with LPS or Pam3CSK4. In this latter study, however, IL-6 and IL-23 levels corresponded to $1 \mathrm{ng} / \mathrm{ml}$ at the best. Herein, we failed to detect IL-17A mRNA expression and production in neutrophils incubated with either LPS 
A
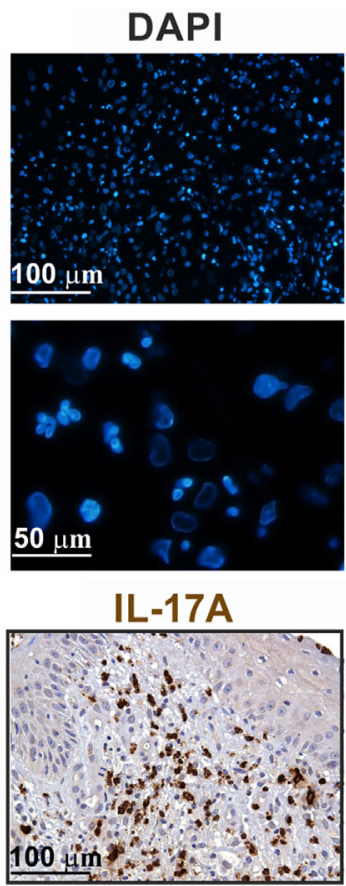

B
IL-17A

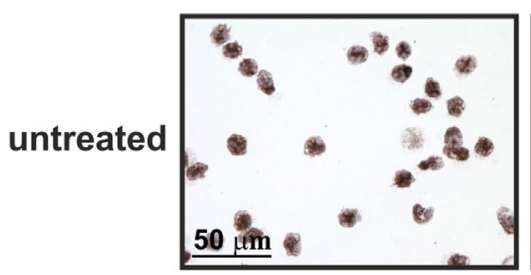

R848

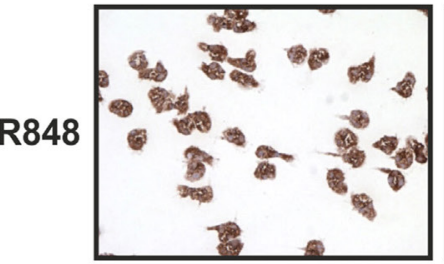

IL-17A
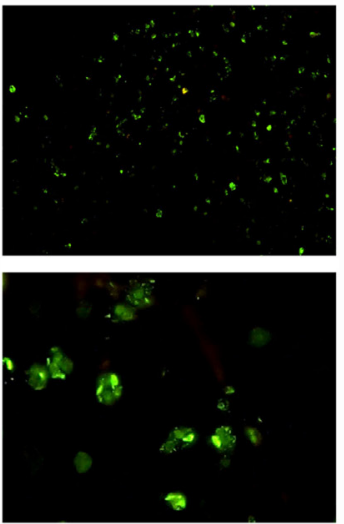

IL-17A

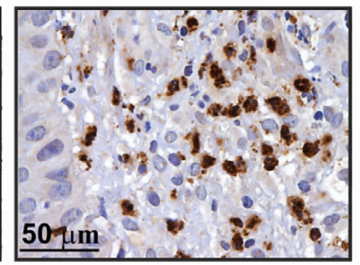

merge
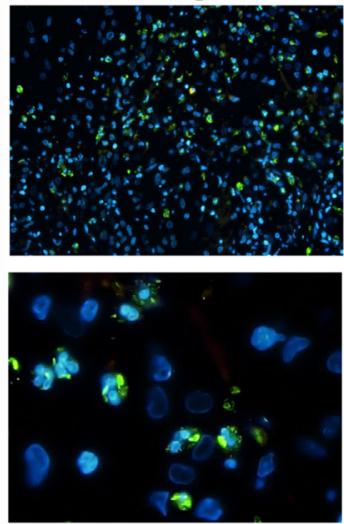

IL-17A/CD66b

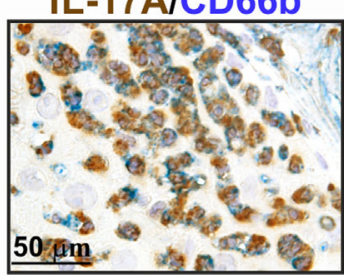

CXCL8

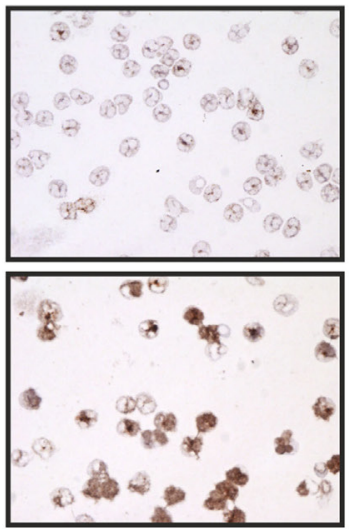

C

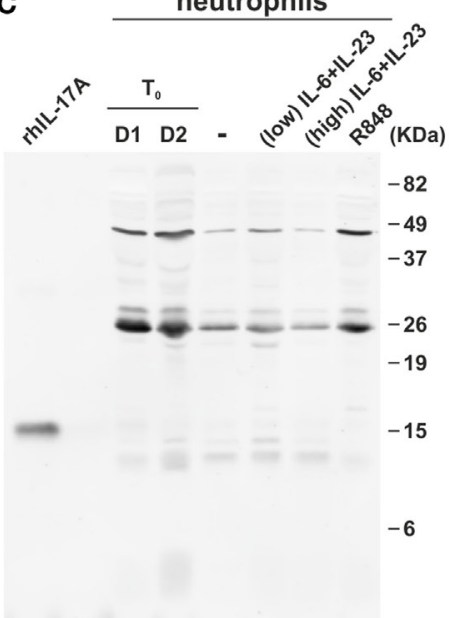

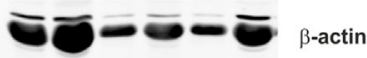

FIGURE 8 | Staining human neutrophils by anti-IL-17A (AF-317-NA) polyclonal antibodies (Abs). (A) Immunofluorescence (top panels) and immunohistochemistry (lower panels) stainings of two FFPE cases of human pustular psoriasis using anti-IL-17A (AF-317-NA) and anti-CD66b Abs (as labeled). Top panels show DAPI, FITC channel, and merge to recognize neutrophil shape; lower panels show different magnification of $\mathrm{IHC}$ and double IHC to characterize IL-17A+ cells with the neutrophil marker CD66b. (B) Cytospins of neutrophils, either untreated (top panels) or treated with $5 \mu \mathrm{M}$ R848 (bottom panels) for $3 \mathrm{~h}$, were stained with anti-IL-17A (AF-317-NA, left panels) and anti-CXCL8 (right panels) Abs. Original magnification 200x [first row in (A) and left image in third row, scale bar 100 $\mu$ m] and $400 \times$ [second row in (A), center/right images in third row in (A), as well as in (B), scale bar $50 \mu \mathrm{m}$ ]. Images of the second row in (A) represent magnifications of images in first row. (C) AF-317-NA immunoblot of lysates from neutrophils either freshly isolated ( $T_{0}$, from two donors) or incubated for $3 \mathrm{~h}$ with or without $2 \mu \mathrm{g} / \mathrm{ml}$ IL-6 plus $0.2 \mu \mathrm{g} / \mathrm{ml} \mathrm{IL-23} \mathrm{(low),} 20 \mu \mathrm{g} / \mathrm{ml}$ IL-6 plus $2 \mu \mathrm{g} / \mathrm{ml}$ IL-23 (high), or $5 \mu \mathrm{M}$ R848. Recombinant human IL-17A (rhlL-17A) was used as positive control. Panels $\mathbf{( B , C )}$ display representative experiments out of two independent ones with similar results.

or Pam3CSK4, even if it is true that they produce IL-6 (62) and IL-23 (our unpublished observations). Whether stimulation of neutrophils with MTB effectively promotes IL-17A expression via endogenous IL-6 and IL-23 remains to be verified. However, no
IL-17A, IL-17B, IL-17C, or IFN $\gamma$ secretion from Mycobacterium bovis Bacille-Calmette Guerin (BCG)-stimulated neutrophils was recently reported (14). It should be also remarked that the purity of neutrophils in studies showing an IL-17 production in 

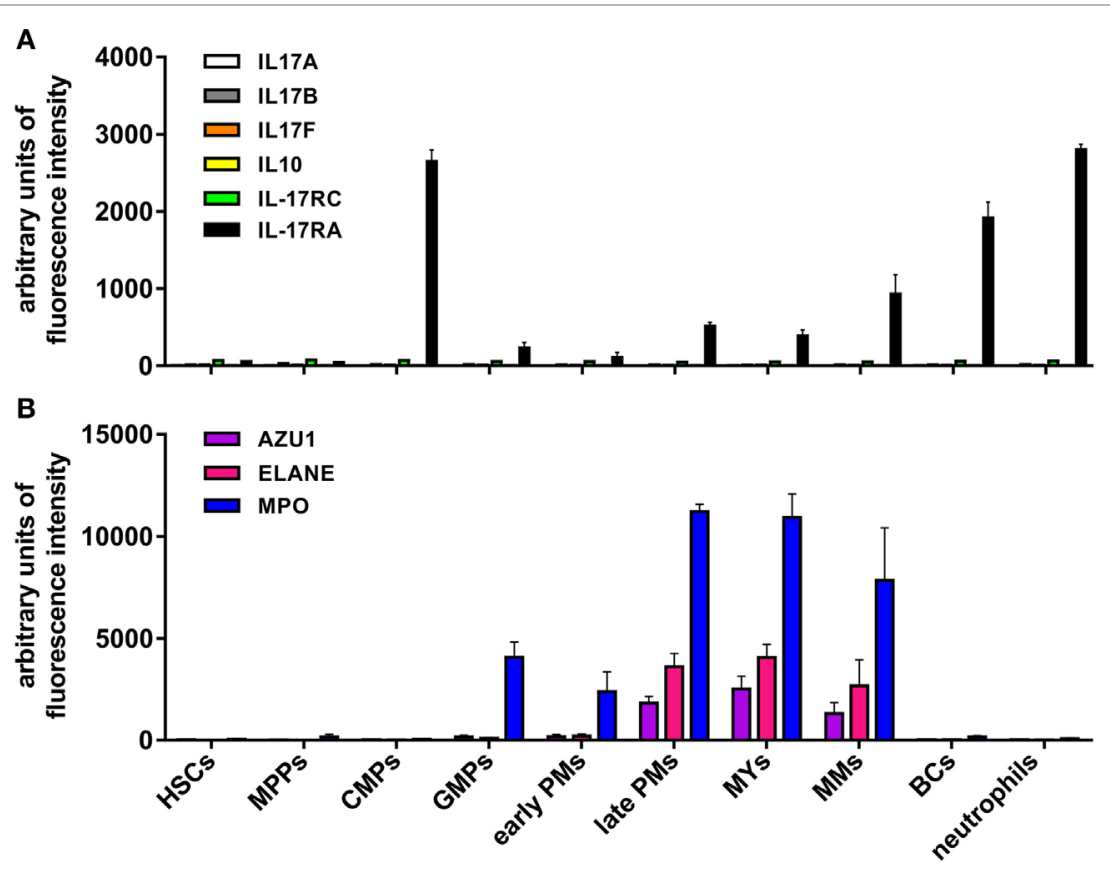

FIGURE 9 | Levels of IL-17A, IL-17B, IL-17F, IL-10, IL-17RC, IL-17RA, azurocidin, neutrophil elastase, and myeloperoxidase (MPO) mRNA expression in neutrophils at different stages of maturation. mRNA expression data derive from Gene Expression Omnibus database (accession number GSE42519) (65). (A) IL-17A, IL-17B, IL-17F, IL-10, IL-17RC, and IL-17RA or (B) azurocidin (AZU1), neutrophil elastase (ELANE), and MPO mRNA expression levels were measured in the following cell types: hematopoietic stem cells (HSCs), multipotent progenitors (MPPs), common myeloid progenitors (CMPs), granulocyte-macrophage progenitors (GMPs), early and late promyelocytes (PMs), myelocytes (MYs), metamyelocytes (MMs), band cells (BCs), and bone marrow polymorphonuclear neutrophil granulocytes. Values represent the mean \pm SEM as calculated from data of the biological replicates present in the database.

response to IL-6 plus IL-23 $(23,29,39,40)$, reported to be $>96 \%$ at the best (29), does not sufficiently secure fully genuine results at least in our opinion.

Nevertheless, we investigated potential mechanisms helping to clarify whether human neutrophils respond to IL-6 plus IL-23 in terms of IL-17A expression or not. ChIP assays revealed that, in resting, as well as in IL-6 plus IL-23-stimulated, neutrophils, but not in Th17 cell lines, the IL17A locus does not contain any $\mathrm{H} 3 \mathrm{~K} 4 \mathrm{me} 1$ and H3K27Ac, which are two histone marks that are usually present in those genomic regions that act as active enhancers (85). On the other hand, the levels of H3K27Ac were found increased at the SOCS3 promoter of neutrophils incubated with IL-6 plus IL-23, consistent with the potentially inducible SOCS3 mRNA transcription. Notably, the complete absence of $\mathrm{H} 3 \mathrm{~K} 4 \mathrm{mel}$ at the $I L 17 \mathrm{~A}$ locus of neutrophils is particularly informative, since such a histone modification is known to precede very early, but time-consuming (86), events necessary for the assembly of the transcriptional machinery, including nucleosomal depletion, H3K27Ac deposition, and enhancer activation (85). Based on our data, it appears that the chromatin at the IL17A locus of human neutrophils likely displays a closed conformation, inaccessible to transcription factors and, consequently, RNA polymerase, ultimately preventing IL-17A mRNA transcription in resting as well as stimulated neutrophils. It is thus very unlikely that $\mathrm{H} 3 \mathrm{~K} 4 \mathrm{me} 1$ modification could be induced within $1 \mathrm{~h}$, e.g., the time-point at which IL-17 mRNA expression in IL-6 plus IL23-stimulated neutrophils has been observed (29,
$39,40)$. Obviously, this does not exclude that there could exist some stimulatory conditions able to modify the chromatin at the IL17A or IL17F loci of human neutrophils.

A variety of studies report the presence of IL-17A $\mathrm{A}^{+}$-neutrophils in sample tissues from many diseases, including psoriasis $(20,25$, $30,32,35,49)$, skin inflammation (27), bullous pemphigoid (28), hidradenitis suppurativa (50), fungal keratitis (26), RA $(31,75)$, ankylosing spondylitis (18), systemic lupus erythematosus (41, 52), human ANCA-associated glomerulonephritis (47), cystic fibrosis $(19,36,44)$, nasal polyps (53), chronic obstructive pulmonary disease (22), lung tissues during bacterial pneumonia (46), alcoholic liver diseases (48), acute renal allograft rejection (42), atherosclerotic plaques (21), cutaneous T cell lymphoma lesions (45), gastric cancer (29), cervical cancer (33), and prostate cancer (51), as revealed by IHC, IF, or intracellular flow cytometry using various commercial anti-IL-17A Abs. Not surprisingly, results occasionally appear discordant. For example, while Moran et al. (31) reported IL-17A-positive synovial tissue neutrophils using the AF-317-NA, van Baarsen et al. (16) show that synovial tissue neutrophils from arthritis patients are not stained by another antibody, namely \#41802. By IHC experiments using AF-317-NA, we too detected IL-17 $\mathrm{A}^{+}$-neutrophils not only in skin sections of psoriasis patients but also in cytospin slides of neutrophils isolated from HDs and incubated for $3 \mathrm{~h}$ with or without R848, at similar levels. By contrast, we found that whole lysates of the same neutrophil populations displayed major signals at levels of proteins having MW not corresponding to that of IL-17A when 
A
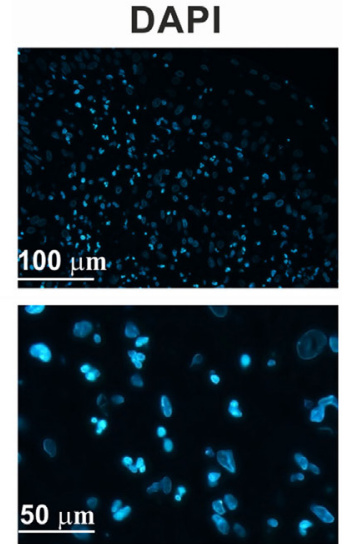

IL-17B

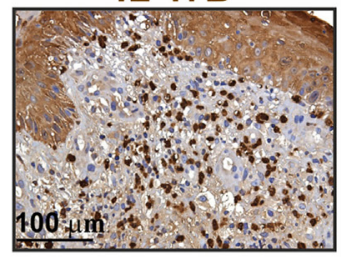

B
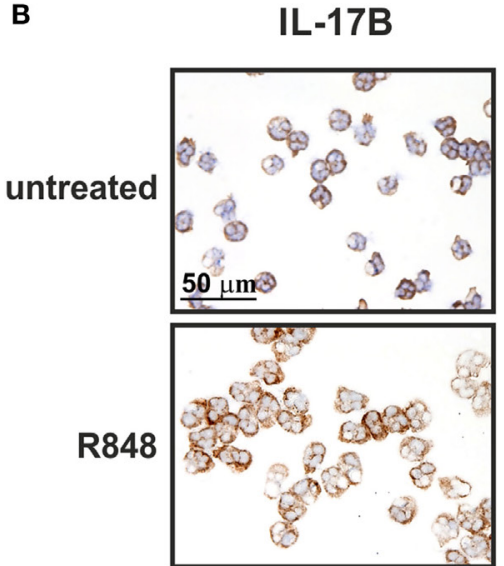

IL-17B
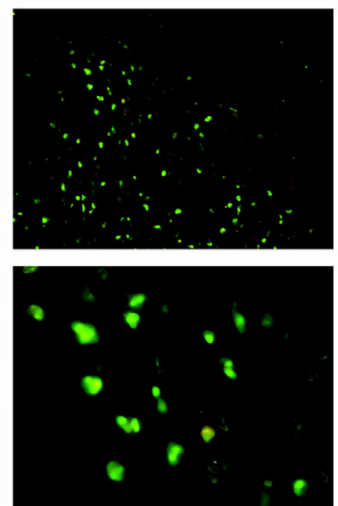

IL-17B

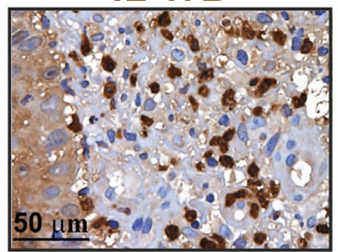

merge
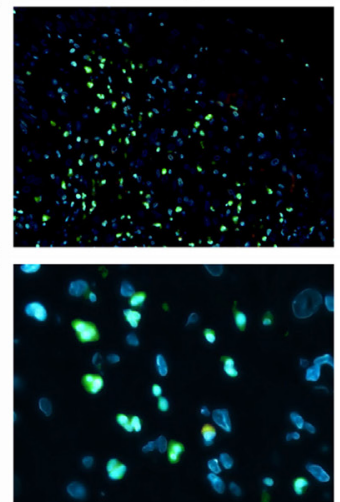

IL-17B/CD66b

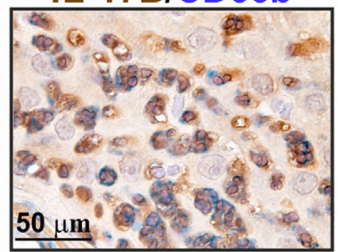

C

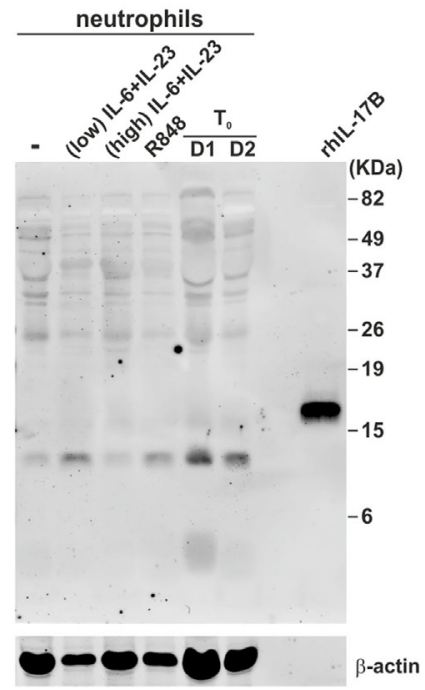

FIGURE 10 | Staining human neutrophils by anti-IL-17B (AF1248) antibodies (Abs). (A) Immunofluorescence (top panels) and immunohistochemistry (lower panels) staining of two FFPE cases of human pustular psoriasis using anti-IL-17B (AF1248) and CD66b Abs (as labeled). Top panels show DAPI, FITC channel, and merge to recognize neutrophil shape; lower panels show different magnification of $\mathrm{IHC}$ and double $\mathrm{IC}$ to characterize IL-17A+ cells with the neutrophil marker CD66b.

(B) Cytospins of neutrophils incubated without (top panel) or with $5 \mu \mathrm{M}$ R848 (bottom panel) for $3 \mathrm{~h}$. Original magnification 200x [first row in (A) and left image in third row, scale bar $100 \mu \mathrm{m}$ ] and 400x [second row in (A), center/right images in third row in (A), as well as in (B), scale bar 50 um]. Images of the second row in (A) represent magnifications of images in first row. (C) AF1248 immunoblot of lysates from neutrophils either freshly isolated (To, from two donors) or incubated for $3 \mathrm{~h}$ with or without $2 \mu \mathrm{g} / \mathrm{ml}$ IL-6 plus $0.2 \mu \mathrm{g} / \mathrm{ml}$ IL-23 (low), $20 \mu \mathrm{g} / \mathrm{ml}$ IL-6 plus $2 \mu \mathrm{g} / \mathrm{ml}$ IL-23 (high), or $5 \mu$ M R848. Recombinant human IL-17B (rhIL-17B) was used as positive control. Panels $\mathbf{( B , C )}$ display representative experiments out of two independent ones with similar results.

immunoblotted with AF-317-NA. Our findings substantially confirm the observations previously made by Tamarozzi et al. (13) who also did not detect any IL-17A expression in highly pure populations of neutrophils $(99.9 \%)$ by using a variety of assays including RT-qPCR, RNA-seq, western blot and ELISA, despite of finding IL-17 $\mathrm{A}^{+}$-neutrophils in Wolbachia Onchocerca volvulus-positive nodules by IHC using AF-317-NA. Notably, by immunoprecipitation experiments followed by mass spectrometry, Tamarozzi et al. (13) also uncovered that both AF-317-NA and \#41802 bind to several proteins expressed in granules (including MPO, lactoferroxin, and lysozyme C) and cytoskeleton (such as keratin and profilin) of neutrophils, while other anti-human IL-17A Abs (sc-6077 from Santa Cruz, and PRS4877 from Sigma) were found to recognize multiple non-specific bands 
in neutrophil immunoblots (13). All in all, data suggest that the IL-17A-positivity of human neutrophils detected by AF-317-NA and \#41802 is, at least in vitro, likely an artifact. Whether these or other anti-IL-17A Abs, including sc-7927 (from Santa Cruz) (33, 43), ab9565 (from Abcam) (37), ab136668 (from Abcam) (46), 500-P07 and 500-P07G (from Peprotech) (43), and eBio64Dec17 (from eBioscience) $(20,26,43)$, are instead reliable in specifically detecting IL-17 $\mathrm{A}^{+}$-neutrophils in tissue samples should be more convincingly established. For instance, in models of skin inflammation resembling psoriasis (27), accumulated neutrophils stained by AF-317-NA were shown to express IL-17 mRNA transcripts. In other studies, tissue neutrophil staining by AF-317-NA was blocked after antibody pre-adsorption with rIL-17A $(18,47)$, or confirmed by costaining of the same section by eBio64DEC17 (47). It is worth recalling that neutrophils express high levels of IL-17RA (12) that could in theory bind exogenously derived IL-17A, consequently leading to a positive signal in IHC or IF experiments without actual intracellular IL-17 production (87), as observed in the case of mast cells (88). Whatever the case is, we would recommend to always validate by multiple investigation methods an eventual detection of IL-17A-positive neutrophils exclusively by IHC, or IF or intracellular flow cytometry $(18,19$, $21,22,28,32-34,36-38,42,43,48-52)$.

Similar concerns can be made for the, to date, reported IL-17B expression by human neutrophils. Accordingly, IL-17B has been detected in neutrophils infiltrating the synovial membrane of RA patients (75) and the stroma of CCR cancer (76) by IHC/IF, as well as in freshly isolated neutrophils by immunoblotting (75), in all cases using \#AF1248 Abs. We also detected IL-17B-positive neutrophils in psoriasis plaques and cytospin slides of freshly isolated neutrophils by IHC using \#AF1248. However, we could not measure any IL-17B in lysates of freshly isolated/activated neutrophils either by using two different commercial ELISA or by \#AF1248 immunoblotting. In the latter experiments, many proteins with MW different from that of rIL-17B were recognized by \#AF1248, thus invalidating at least the cytospin results. Intriguingly, Kouri et al. (75) did detect IL-17B protein in lysates of neutrophils (95\% pure), by both ELISA and immunoblotting using \#AF1248. However, these authors showed only a portion of the western blot (75), thus rendering impossible to know whether additional major proteins were recognized by \#AF1248. Curiously, we, Tamarozzi et al. (13) and Kouri et al. (75), all found that human neutrophils do not transcribe IL-17B mRNA under resting or activating condition. Furthermore, no IL-17B secretion from BCG-stimulated neutrophils was recently shown (14). In such regard, Koury et al. (75) suggested that IL-17B is synthesized only at the promyelocyte and myelocyte stage in the bone marrow, disappearing in mature neutrophils. However, our analysis of transcriptomes generated from all types of bone marrow cell populations (65) revealed that, similarly to IL-17A, also IL-17B is never transcribed during the different stages of neutrophil maturation. Altogether, data suggest that human

\section{REFERENCES}

1. Amatya N, Garg AV, Gaffen SL. IL-17 signaling: the Yin and the Yang. Trends Immunol (2017) 38(5):310-22. doi:10.1016/j.it.2017.01.006 neutrophils do not express IL-17B in vitro. They also suggest that the positive staining of neutrophils by IHC using AF1248 is likely due to a non-specific, IL-17B independent, binding of these Abs.

In conclusion, data shown in this study are consistent with the notion that human neutrophils are unable to express and produce IL-17A, IL-17B, or IL-17F in vitro.

\section{ETHICS STATEMENT}

This study was carried out in accordance with the recommendations of Ethic Committee of the Azienda Ospedaliera Universitaria Integrata di Verona (Italy). All the experimental protocols were approved by the Ethic Committee and all subjects gave written informed consent in accordance with the Declaration of Helsinki.

\section{AUTHOR CONTRIBUTIONS}

All authors were involved in discussing and drafting the article, approved the final version to be published, and had full access to all data, taking responsibility for their integrity and analysis accuracy. In particular, NT, FA-S, SG, EG, SL, LG, and FC performed the experiments; FA-S, FB-A, NT, SL, WV, and MC analyzed the results; GG provided patients; and FS, NT, AM, WV, and MC conceived the experiments and wrote the paper.

\section{ACKNOWLEDGMENTS}

We thank Luigina Romani (University of Perugia, Perugia, Italy) for inactivated Aspergillus Fumigatus hyphae and conidia, Alessio Mazzoni and Francesco Annunziato (University of Firenze, Firenze, Italy) for Th17 clones, Alessia Farinazzo and Bruno Bonetti (University of Verona, Verona, Italy) for protein lysate of human cerebral cortex and Gioacchino Natoli (Humanitas University, Rozzano, Milan, Italy) for his support and discussion on ChIP-seq experiments.

\section{FUNDING}

This work was supported by grants from Associazione Italiana per la Ricerca sul Cancro (AIRC, IG-20339) and Ministero dell'Istruzione, dell'Università e della Ricerca (PRIN 2015YYKPNN) to MC, and from Novartis Farma SpA (Origgio, Italia) to AM. FA-S is supported by Brazilian fellowship from Coordenação de Aperfeiçoamento de Pessoal de Nível Superior (CAPES, no Processo: 99999.013628/2013-05).

\section{SUPPLEMENTARY MATERIAL}

The Supplementary Material for this article can be found online at https://www.frontiersin.org/articles/10.3389/fimmu.2018.00795/ full\#supplementary-material.

2. Hymowitz SG, Filvaroff EH, Yin JP, Lee J, Cai L, Risser P, et al. IL-17s adopt a cystine knot fold: structure and activity of a novel cytokine, IL-17F, and implications for receptor binding. EMBO J (2001) 20(19):5332-41. doi:10.1093/ emboj/20.19.5332 
3. Gaffen SL, Jain R, Garg AV, Cua DJ. The IL-23-IL-17 immune axis: from mechanisms to therapeutic testing. Nat Rev Immunol (2014) 14(9):585-600. doi:10.1038/nri3707

4. Wright JF, Guo Y, Quazi A, Luxenberg DP, Bennett F, Ross JF, et al. Identification of an interleukin 17F/17A heterodimer in activated human CD4+ T cells. J Biol Chem (2007) 282(18):13447-55. doi:10.1074/jbc.M700499200

5. Veldhoen M. Interleukin 17 is a chief orchestrator of immunity. Nat Immunol (2017) 18(6):612-21. doi:10.1038/ni.3742

6. Schwarzenberger P, La Russa V, Miller A, Ye P, Huang W, Zieske A, et al. IL-17 stimulates granulopoiesis in mice: use of an alternate, novel gene therapy-derived method for in vivo evaluation of cytokines. J Immunol (1998) 161(11):6383-9.

7. McAleer JP, Kolls JK. Mechanisms controlling Th17 cytokine expression and host defense. J Leukoc Biol (2011) 90(2):263-70. doi:10.1189/jlb.0211099

8. Miossec P, Kolls JK. Targeting IL-17 and TH17 cells in chronic inflammation. Nat Rev Drug Discov (2012) 11(10):763-76. doi:10.1038/nrd3794

9. Cua DJ, Tato CM. Innate IL-17-producing cells: the sentinels of the immune system. Nat Rev Immunol (2010) 10(7):479-89. doi:10.1038/nri2800

10. Scapini P, Tamassia N, Pucillo C, Cassatella MA. Granulocytes and mast cells. 7th ed. In: Paul WE, editor. Fundamental Immunology. Philadelphia, PA: Wolters Kluwer Health/Lippincott Williams \& Wilkins (2013). p. 468-86.

11. Tecchio C, Scapini P, Pizzolo G, Cassatella MA. On the cytokines produced by human neutrophils in tumors. Semin Cancer Biol (2013) 23(3):159-70. doi:10.1016/j.semcancer.2013.02.004

12. Pelletier M, Maggi L, Micheletti A, Lazzeri E, Tamassia N, Costantini C, et al. Evidence for a cross-talk between human neutrophils and Th17 cells. Blood (2010) 115(2):335-43. doi:10.1182/blood-2009-04-216085

13. Tamarozzi F, Wright HL, Thomas HB, Edwards SW, Taylor MJ. A lack of confirmation with alternative assays questions the validity of IL-17A expression in human neutrophils using immunohistochemistry. Immunol Lett (2014) 162(2 Pt B):194-8. doi:10.1016/j.imlet.2014.10.025

14. Tenland E, Hakansson G, Alaridah N, Lutay N, Ronnholm A, Hallgren O, et al. Innate immune responses after airway epithelial stimulation with Mycobacterium bovis bacille-Calmette Guerin. PLoS One (2016) 11(10): e0164431. doi:10.1371/journal.pone.0164431

15. Yamanaka K, Yamagiwa A, Akeda T, Kondo M, Kakeda M, Habe K, et al. Neutrophils are not the dominant interleukin-17 producer in psoriasis. J Dermatol (2017) 44(7):e170-1. doi:10.1111/1346-8138.13807

16. van Baarsen LGM, Lebre MC, van der Coelen D, Aarrass S, Tang MW, Ramwadhdoebe $\mathrm{TH}$, et al. Heterogeneous expression pattern of interleukin 17A (IL-17A), IL-17F and their receptors in synovium of rheumatoid arthritis, psoriatic arthritis and osteoarthritis: possible explanation for nonresponse to anti-IL-17 therapy? Arthritis Res Ther (2014) 16(4):426. doi:10.1186/s13075014-0426-z

17. Nadkarni S, Smith J, Sferruzzi-Perri AN, Ledwozyw A, Kishore M, Haas R, et al. Neutrophils induce proangiogenic T cells with a regulatory phenotype in pregnancy. Proc Natl Acad Sci U S A (2016) 113(52):E8415-24. doi:10.1073/ pnas. 1611944114

18. Appel H, Maier R, Wu P, Scheer R, Hempfing A, Kayser R, et al. Analysis of IL-17(+) cells in facet joints of patients with spondyloarthritis suggests that the innate immune pathway might be of greater relevance than the Th17mediated adaptive immune response. Arthritis Res Ther (2011) 13(3):R95. doi:10.1186/ar3370

19. Brodlie M, McKean MC, Johnson GE, Anderson AE, Hilkens CM, Fisher AJ, et al. Raised interleukin-17 is immunolocalised to neutrophils in cystic fibrosis lung disease. Eur Respir J (2011) 37(6):1378-85. doi:10.1183/09031936. 00067110

20. Dyring-Andersen B, Honore TV, Madelung A, Bzorek M, Simonsen S, Clemmensen SN, et al. Interleukin (IL)-17A and IL-22-producing neutrophils in psoriatic skin. Br J Dermatol (2017) 177(6):e321-2. doi:10.1111/bjd.15533

21. de Boer OJ, van der Meer JJ, Teeling P, van der Loos CM, Idu MM, van Maldegem F, et al. Differential expression of interleukin-17 family cytokines in intact and complicated human atherosclerotic plaques. J Pathol (2010) 220(4):499-508. doi:10.1002/path.2667

22. Eustace A, Smyth LJC, Mitchell L, Williamson K, Plumb J, Singh D. Identification of cells expressing IL-17A and IL-17F in the lungs of patients with COPD. Chest (2011) 139(5):1089-100. doi:10.1378/chest.10-0779

23. Halwani R, Sultana A, Vazquez-Tello A, Jamhawi A, Al-Masri AA, Al-Muhsen S. Th-17 regulatory cytokines IL-21, IL-23, and IL-6 enhance neutrophil production of IL-17 cytokines during asthma. J Asthma (2017) 54(9):893-904. doi:10.1080/02770903.2017.1283696

24. Hu S, He W, Du X, Yang J, Wen Q, Zhong XP, et al. IL-17 production of neutrophils enhances antibacteria ability but promotes arthritis development during Mycobacterium tuberculosis infection. EBioMed (2017) 23:88-99. doi:10.1016/j.ebiom.2017.08.001

25. Kakeda M, Schlapbach C, Danelon G, Tang MM, Cecchinato V, Yawalkar N, et al. Innate immune cells express IL-17A/F in acute generalized exanthematous pustulosis and generalized pustular psoriasis. Arch Dermatol Res (2014) 306(10):933-8. doi:10.1007/s00403-014-1488-0

26. Karthikeyan RS, Vareechon C, Prajna NV, Dharmalingam K, Pearlman E, Lalitha P. Interleukin 17 expression in peripheral blood neutrophils from fungal keratitis patients and healthy cohorts in southern India. J Infect Dis (2015) 211(1):130-4. doi:10.1093/infdis/jiu381

27. Keijsers R, Hendriks AGM, van Erp PEJ, van Cranenbroek B, van de Kerkhof PCM, Koenen $\mathrm{H}$, et al. In vivo induction of cutaneous inflammation results in the accumulation of extracellular trap-forming neutrophils expressing RORgammat and IL-17. J Invest Dermatol (2014) 134(5):1276-84. doi:10.1038/ jid.2013.526

28. Le Jan S, Plee J, Vallerand D, Dupont A, Delanez E, Durlach A, et al. Innate immune cell-produced IL-17 sustains inflammation in bullous pemphigoid. J Invest Dermatol (2014) 134(12):2908-17. doi:10.1038/jid.2014.263

29. Li TJ, Jiang YM, Hu YF, Huang L, Yu J, Zhao LY, et al. Interleukin-17-producing neutrophils link inflammatory stimuli to disease progression by promoting angiogenesis in gastric cancer. Clin Cancer Res (2017) 23(6):1575-85. doi:10.1158/1078-0432.ccr-16-0617

30. Lin AM, Rubin CJ, Khandpur R, Wang JY, Riblett M, Yalavarthi S, et al. Mast cells and neutrophils release IL-17 through extracellular trap formation in psoriasis. JImmunol (2011) 187(1):490-500. doi:10.4049/jimmunol. 1100123

31. Moran EM, Heydrich R, Ng CT, Saber TP, McCormick J, Sieper J, et al. IL-17A expression is localised to both mononuclear and polymorphonuclear synovial cell infiltrates. PLoS One (2011) 6(8):e24048. doi:10.1371/journal. pone. 0024048

32. Patel DD, Lee DM, Kolbinger F, Antoni C. Effect of IL-17A blockade with secukinumab in autoimmune diseases. Ann Rheum Dis (2013) 72(Suppl 2):ii116-23. doi:10.1136/annrheumdis-2012-202371

33. Punt S, Fleuren GJ, Kritikou E, Lubberts E, Trimbos JB, Jordanova ES, et al. Angels and demons: Th17 cells represent a beneficial response, while neutrophil IL-17 is associated with poor prognosis in squamous cervical cancer. Oncoimmunology (2015) 4(1):e984539. doi:10.4161/2162402x.2014. 984539

34. Ramirez-Velazquez C, Castillo EC, Guido-Bayardo L, Ortiz-Navarrete V. IL-17-producing peripheral blood CD177+ neutrophils increase in allergic asthmatic subjects. Allergy Asthma Clin Immunol (2013) 9(1):23. doi:10.1186/ 1710-1492-9-23

35. Reich K, Papp KA, Matheson RT, Tu JH, Bissonnette R, Bourcier M, et al. Evidence that a neutrophil-keratinocyte crosstalk is an early target of IL-17A inhibition in psoriasis. Exp Dermatol (2015) 24(7):529-35. doi:10.1111/ exd. 12710

36. Tan HL, Regamey N, Brown S, Bush A, Lloyd CM, Davies JC. The Th17 pathway in cystic fibrosis lung disease. Am J Respir Crit Care Med (2011) 184(2):252-8. doi:10.1164/rccm.201102-0236OC

37. Rodrigues-Diez R, Aroeira LS, Orejudo M, Bajo MA, Heffernan JJ, RodriguesDiez RR, et al. IL-17A is a novel player in dialysis-induced peritoneal damage. Kidney Int (2014) 86(2):303-15. doi:10.1038/ki.2014.33

38. Tan Z, Jiang R, Wang X, Wang Y, Lu L, Liu Q, et al. RORgammat+IL-17+ neutrophils play a critical role in hepatic ischemia-reperfusion injury. J Mol Cell Biol (2013) 5(2):143-6. doi:10.1093/jmcb/mjs065

39. Taylor PR, Roy S, Leal SM Jr, Sun Y, Howell SJ, Cobb BA, et al. Activation of neutrophils by autocrine IL-17A-IL-17RC interactions during fungal infection is regulated by IL-6, IL-23, RORgammat and dectin-2. Nat Immunol (2014) 15(2):143-51. doi:10.1038/ni.2797

40. Taylor PR, Roy S, Meszaros EC, Sun Y, Howell SJ, Malemud CJ, et al. JAK/ STAT regulation of Aspergillus fumigatus corneal infections and IL-6/23stimulated neutrophil, IL-17, elastase, and MMP9 activity. J Leukoc Biol (2016) 100(1):213-22. doi:10.1189/jlb.4A1015-483R

41. Villanueva E, Yalavarthi S, Berthier CC, Hodgin JB, Khandpur R, Lin AM, et al. Netting neutrophils induce endothelial damage, infiltrate tissues, and 
expose immunostimulatory molecules in systemic lupus erythematosus. J Immunol (2011) 187(1):538-52. doi:10.4049/jimmunol.1100450

42. Yapici U, Kers J, Bemelman FJ, Roelofs JJ, Groothoff JW, van der Loos CM, et al. Interleukin-17 positive cells accumulate in renal allografts during acute rejection and are independent predictors of worse graft outcome. Transpl Int (2011) 24(10):1008-17. doi:10.1111/j.1432-2277.2011.01302.x

43. Yapici U, Roelofs JJ, Florquin S. The importance of testing anti-IL-17 antibodies from different suppliers. Am J Transplant (2012) 12(2):504-5. doi:10.1111/j.1600-6143.2011.03867.x

44. Taylor PR, Bonfield TL, Chmiel JF, Pearlman E. Neutrophils from F508del cystic fibrosis patients produce IL-17A and express IL-23-dependent IL-17RC. Clin Immunol (2016) 170:53-60. doi:10.1016/j.clim.2016.03.016

45. Fontao L, Brembilla NC, Masouye I, Kaya G, Prins C, Dupin N, et al. Interleukin-17 expression in neutrophils and Th17 cells in cutaneous T-cell lymphoma associated with neutrophilic infiltrate of the skin. Br J Dermatol (2012) 166(3):687-9. doi:10.1111/j.1365-2133.2011.10647.x

46. Cai S, Batra S, Langohr I, Iwakura Y, Jeyaseelan S. IFN-gamma induction by neutrophil-derived IL-17A homodimer augments pulmonary antibacterial defense. Mucosal Immunol (2016) 9(3):718-29. doi:10.1038/mi.2015.95

47. Velden J, Paust HJ, Hoxha E, Turner JE, Steinmetz OM, Wolf G, et al. Renal IL-17 expression in human ANCA-associated glomerulonephritis. Am J Physiol Renal Physiol (2012) 302(12):F1663-73. doi:10.1152/ajprenal.00683.2011

48. Lemmers A, Moreno C, Gustot T, Marechal R, Degre D, Demetter P, et al. The interleukin-17 pathway is involved in human alcoholic liver disease. Hepatology (2009) 49(2):646-57. doi:10.1002/hep.22680

49. Res PC, Piskin G, de Boer OJ, van der Loos CM, Teeling P, Bos JD, et al. Overrepresentation of IL-17A and IL-22 producing CD8 T cells in lesional skin suggests their involvement in the pathogenesis of psoriasis. PLoS One (2010) 5(11):e14108. doi:10.1371/journal.pone.0014108

50. Lima AL, Karl I, Giner T, Poppe H, Schmidt M, Presser D, et al. Keratinocytes and neutrophils are important sources of proinflammatory molecules in hidradenitis suppurativa. Br J Dermatol (2016) 174(3):514-21. doi:10.1111/ bjd. 14214

51. Vykhovanets EV, Maclennan GT, Vykhovanets OV, Gupta S. IL-17 expression by macrophages is associated with proliferative inflammatory atrophy lesions in prostate cancer patients. Int J Clin Exp Pathol (2011) 4(6):552-65.

52. Lopez P, Rodriguez-Carrio J, Caminal-Montero L, Mozo L, Suarez A. A pathogenic IFNalpha, BLyS and IL-17 axis in systemic lupus erythematosus patients. Sci Rep (2016) 6:20651. doi:10.1038/srep20651

53. Derycke L, Zhang N, Holtappels G, Dutre T, Bachert C. IL-17A as a regulator of neutrophil survival in nasal polyp disease of patients with and without cystic fibrosis. J Cyst Fibros (2012) 11(3):193-200. doi:10.1016/j.jcf.2011.11.007

54. Schon MP, Broekaert SM, Erpenbeck L. Sexy again: the renaissance of neutrophils in psoriasis. Exp Dermatol (2017) 26(4):305-11. doi:10.1111/exd.13067

55. Finlay AY. Current severe psoriasis and the rule of tens. Br J Dermatol (2005) 152(5):861-7. doi:10.1111/j.1365-2133.2005.06502.x

56. Calzetti F, Tamassia N, Arruda-Silva F, Gasperini S, Cassatella MA. The importance of being "pure" neutrophils. JAllergy Clin Immunol (2017) 139(1):352-5.e6. doi:10.1016/j.jaci.2016.06.025

57. Bozza S, Gaziano R, Spreca A, Bacci A, Montagnoli C, di Francesco P, et al. Dendritic cells transport conidia and hyphae of Aspergillus fumigatus from the airways to the draining lymph nodes and initiate disparate $T h$ responses to the fungus. J Immunol (2002) 168(3):1362-71. doi:10.4049/jimmunol.168.3.1362

58. Annunziato F, Cosmi L, Santarlasci V, Maggi L, Liotta F, Mazzinghi B, et al. Phenotypic and functional features of human Th17 cells. J Exp Med (2007) 204(8):1849-61. doi:10.1084/jem.20070663

59. Scapini P, Calzetti F, Cassatella MA. On the detection of neutrophil-derived vascular endothelial growth factor (VEGF). JImmunol Methods (1999) 232(1-2):121-9. doi:10.1016/S0022-1759(99)00170-2

60. Cassatella MA, Guasparri I, Ceska M, Bazzoni F, Rossi F. Interferon-gamma inhibits interleukin-8 production by human polymorphonuclear leucocytes. Immunology (1993) 78(2):177-84.

61. Scapini P, Nardelli B, Nadali G, Calzetti F, Pizzolo G, Montecucco C, et al. G-CSF-stimulated neutrophils are a prominent source of functional BLyS. J Exp Med (2003) 197(3):297-302. doi:10.1084/jem.20021343

62. Zimmermann M, Aguilera FB, Castellucci M, Rossato M, Costa S, Lunardi C, et al. Chromatin remodelling and autocrine TNFalpha are required for optimal interleukin-6 expression in activated human neutrophils. Nat Commun (2015) 6:6061. doi:10.1038/ncomms7061
63. Muller PY, Janovjak H, Miserez AR, Dobbie Z. Processing of gene expression data generated by quantitative real-time RT-PCR. Biotechniques (2002) 32(6): $1372-4$.

64. Langmead B, Trapnell C, Pop M, Salzberg SL. Ultrafast and memory-efficient alignment of short DNA sequences to the human genome. Genome Biol (2009) 10(3):R25. doi:10.1186/gb-2009-10-3-r25

65. Rapin N, Bagger FO, Jendholm J, Mora-Jensen H, Krogh A, Kohlmann A, et al. Comparing cancer vs normal gene expression profiles identifies new disease entities and common transcriptional programs in AML patients. Blood (2014) 123(6):894-904. doi:10.1182/blood-2013-02-485771

66. Zimmermann M, Arruda-Silva F, Bianchetto-Aguilera F, Finotti G, Calzetti F, Scapini P, et al. IFNalpha enhances the production of IL-6 by human neutrophils activated via TLR8. Sci Rep (2016) 6:19674. doi:10.1038/ srep19674

67. Crepaldi L, Silveri L, Calzetti F, Pinardi C, Cassatella MA. Molecular basis of the synergistic production of IL-1 receptor antagonist by human neutrophils stimulated with IL-4 and IL-10. Int Immunol (2002) 14(10):1145-53. doi:10.1093/intimm/dxf079

68. Moore EE, Presnell S, Garrigues U, Guilbot A, LeGuern E, Smith D, et al. Expression of IL-17B in neurons and evaluation of its possible role in the chromosome 5q-linked form of Charcot-Marie-tooth disease. Neuromuscul Disord (2002) 12(2):141-50. doi:10.1016/S0960-8966(01)00250-4

69. Heintzman ND, Stuart RK, Hon G, Fu Y, Ching CW, Hawkins RD, et al. Distinct and predictive chromatin signatures of transcriptional promoters and enhancers in the human genome. Nat Genet (2007) 39(3):311-8. doi:10.1038/ ng1966

70. Tamassia N, Zimmermann M, Castellucci M, Ostuni R, Bruderek K, Schilling B, et al. Cutting edge: an inactive chromatin configuration at the IL-10 locus in human neutrophils. J Immunol (2013) 190(5):1921-5. doi:10.4049/jimmunol. 1203022

71. Northrup DL, Zhao K. Application of ChIP-Seq and related techniques to the study of immune function. Immunity (2011) 34(6):830-42. doi:10.1016/ j.immuni.2011.06.002

72. Bernstein BE, Stamatoyannopoulos JA, Costello JF, Ren B, Milosavljevic A, Meissner A, et al. The NIH roadmap epigenomics mapping consortium. Nat Biotechnol (2010) 28(10):1045-8. doi:10.1038/nbt1010-1045

73. Zhang L, Badgwell DB, Bevers JJ III, Schlessinger K, Murray PJ, Levy DE, et al. IL-6 signaling via the STAT3/SOCS3 pathway: functional analysis of the conserved STAT3 N-domain. Mol Cell Biochem (2006) 288(1-2):179-89. doi:10.1007/s11010-006-9137-3

74. Theilgaard-Monch K, Jacobsen LC, Borup R, Rasmussen T, Bjerregaard MD, Nielsen FC, et al. The transcriptional program of terminal granulocytic differentiation. Blood (2005) 105(4):1785-96. doi:10.1182/blood-2004-08-3346

75. Kouri VP, Olkkonen J, Ainola M, Li TF, Bjorkman L, Konttinen YT, et al. Neutrophils produce interleukin-17B in rheumatoid synovial tissue. Rheumatology (Oxford) (2014) 53(1):39-47. doi:10.1093/rheumatology/ket309

76. Al-Samadi A, Moossavi S, Salem A, Sotoudeh M, Tuovinen SM, Konttinen YT, et al. Distinctive expression pattern of interleukin-17 cytokine family members in colorectal cancer. Tumour Biol (2016) 37(2):1609-15. doi:10.1007/ s13277-015-3941-x

77. Ferretti S, Bonneau O, Dubois GR, Jones CE, Trifilieff A. IL-17, produced by lymphocytes and neutrophils, is necessary for lipopolysaccharide-induced airway neutrophilia: IL-15 as a possible trigger. J Immunol (2003) 170(4):2106-12. doi:10.4049/jimmunol.170.4.2106

78. Werner JL, Gessner MA, Lilly LM, Nelson MP, Metz AE, Horn D, et al. Neutrophils produce interleukin 17A (IL-17A) in a dectin-1- and IL-23dependent manner during invasive fungal infection. Infect Immun (2011) 79(10):3966-77. doi:10.1128/IAI.05493-11

79. Katayama M, Ohmura K, Yukawa N, Terao C, Hashimoto M, Yoshifuji H, et al. Neutrophils are essential as a source of IL-17 in the effector phase of arthritis. PLoS One (2013) 8(5):e62231. doi:10.1371/journal.pone.0062231

80. Li L, Huang L, Vergis AL, Ye H, Bajwa A, Narayan V, et al. IL-17 produced by neutrophils regulates IFN-gamma-mediated neutrophil migration in mouse kidney ischemia-reperfusion injury. JClin Invest (2010) 120(1):331-42. doi:10.1172/jci38702

81. Hoshino A, Nagao T, Nagi-Miura N, Ohno N, Yasuhara M, Yamamoto K, et al. MPO-ANCA induces IL-17 production by activated neutrophils in vitro via classical complement pathway-dependent manner. J Autoimmun (2008) 31(1):79-89. doi:10.1016/j.jaut.2008.03.006 
82. Huppler AR, Verma AH, Conti HR, Gaffen SL. Neutrophils do not express IL-17A in the context of acute oropharyngeal candidiasis. Pathogens (2015) 4(3):559-72. doi:10.3390/pathogens4030559

83. Price AE, Reinhardt RL, Liang HE, Locksley RM. Marking and quantifying IL-17A-producing cells in vivo. PLoS One (2012) 7(6):e39750. doi:10.1371/ journal.pone.0039750

84. Davey MS, Tamassia N, Rossato M, Bazzoni F, Calzetti F, Bruderek K, et al. Failure to detect production of IL-10 by activated human neutrophils. Nat Immunol (2011) 12(11):1017-8. doi:10.1038/ni.2111

85. Calo E, Wysocka J. Modification of enhancer chromatin: what, how, and why? Mol Cell (2013) 49(5):825-37. doi:10.1016/j.molcel.2013.01.038

86. Ostuni R, Piccolo V, Barozzi I, Polletti S, Termanini A, Bonifacio S, et al. Latent enhancers activated by stimulation in differentiated cells. Cell (2013) 152(1-2):157-71. doi:10.1016/j.cell.2012.12.018

87. Huppler AR, Gaffen SL. Editorial: fake it 'til you make it: mast cells acquire IL-17 exogenously. J Leukoc Biol (2016) 100(3):445-6. doi:10.1189/ jlb.3CE0216-071R
88. Noordenbos T, Blijdorp I, Chen S, Stap J, Mul E, Canete JD, et al. Human mast cells capture, store, and release bioactive, exogenous IL-17A. J Leukoc Biol (2016) 100(3):453-62. doi:10.1189/jlb.3HI1215-542R

Conflict of Interest Statement: The authors declare that the research was conducted in the absence of any commercial or financial relationships that could be construed as a potential conflict of interest.

Copyright (c) 2018 Tamassia, Arruda-Silva, Calzetti, Lonardi, Gasperini, Gardiman, Bianchetto-Aguilera, Gatta, Girolomoni, Mantovani, Vermi and Cassatella. This is an open-access article distributed under the terms of the Creative Commons Attribution License (CC BY). The use, distribution or reproduction in other forums is permitted, provided the original author(s) and the copyright owner are credited and that the original publication in this journal is cited, in accordance with accepted academic practice. No use, distribution or reproduction is permitted which does not comply with these terms. 